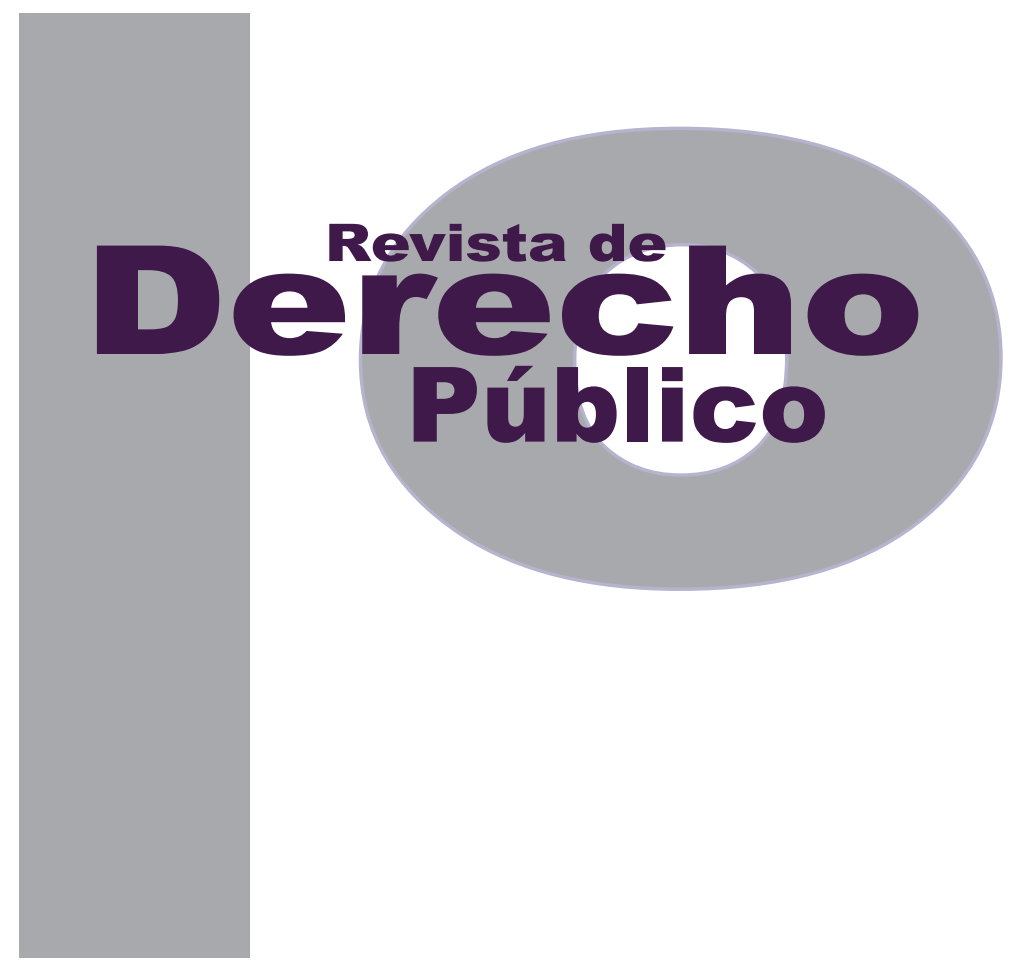

\title{
LOS RETOS DE LOS COMITÉS TERRITORIALES DE JUSTICIA TRANSICIONAL EN LA IMPLEMENTACIÓN DE LA LEY DE VÍCTIMAS
}

\author{
MARiana CAStrellón Pérez \\ JuAn CAMilo TABorda Burgos \\ JULIANA VARGAS GÓMEZ \\ Artículo de reflexión
}

DOI: http://dx.doi.org/10.15425/redepub.34.2015.15

Universidad de los Andes

Facultad de Derecho

Revista de Derecho Público N. ${ }^{\circ} 34$

Enero - Junio de 2015. ISSN 1909-7778 


\title{
Los retos de los comités territoriales de justicia transicional en la implementación de la Ley de Víctimas
}

\section{Resumen}

Este artículo tiene el propósito de describir el funcionamiento de los comités territoriales de justicia transicional (CTJT) que operan en las entidades territoriales departamentales, municipales y distritales, e identificar los retos que actualmente enfrentan en la implementación de la Ley de Víctimas. Se identificaron dos tipos de retos. Los retos externos: (1) la articulación del sistema de atención y reparación de las víctimas y el ciclo de planeación; (2) la aplicación diferencial de la política de atención y reparación a las víctimas entre las diferentes entidades territoriales y (3) la articulación entre los стנт y otras instancias del Estado que adelantan procesos que también involucran a las víctimas. Además de estos, se encuentran los retos internos: (1) frente a la participación de los representantes de las víctimas y (2) frente a la interpretación de las normas que regulan el funcionamiento de los стJт.

Palabras clave: comités territoriales de justicia transicional, entidades territoriales, atención y reparación, víctimas del conflicto, retos.

\section{Transitional justice local committees' challenges in implementing the victims' law}

\begin{abstract}
This article aims to describe the operation of the Transitional Justice Local Committees, which have jurisdiction in departments, municipalities and districts of Colombia. It also aims to identify the challenges that these committees currently face in the implementation of the Victims Law. Two types of challenges can be identified for the Transitional Justice Local Committees in the implementation of the Victims Law. External challenges: (1) articulation between the attention and reparation system for victims and the planning cycle; (2) differential application of the victims' policy in each local entity and (3) challenges in the articulation of the Committees and other public entities who also deal with attention to victims. Besides these, the internal challenges are: (1) participation of the victims' representatives at the Committee and (2) challenges in the interpretation of the legal framework that regulates these Committees.
\end{abstract}

Key words: Transitional Justice Local Committees, local entities, attention and reparation, victims and challenges.

\section{Os desafios dos comitês territoriais de justiça transicional na implementação da Lei de Vítimas}

\section{Resumo}

Este artigo tem o propósito de descrever o funcionamento dos comitês territoriais de justiça transicional (cтJ) que operam nas entidades territoriais departamentais, municipais e distritais, e identificar os desafios que atualmente enfrentam na implementação da Lei de Vítimas. Foram identificados dois tipos de desafios. Os desafios externos: (1) a articulação do sistema de atenção e reparação das vítimas e o ciclo de planejamento; (2) a aplicação diferencial da política de atenção e reparação às vítimas entre as diferentes entidades territoriais e (3) a articulação entre os cTJ e outras instâncias do Estado que adiantam processos que também envolvem as vítimas. Além destes, se encontram os desafios internos: (1) frente à participação dos representantes das vítimas e (2) frente à interpretação das normas que regulam o funcionamento dos cтJ.

Palavras-chave: comitês territoriais de justiça transicional, entidades territoriais, atenção e reparação, vítimas do conflito, desafios. 


\title{
Los retos de los comités territoriales de justicia transicional en la implementación de la Ley de Víctimas ${ }^{*}$
}

\author{
Mariana Castrellón Pérez ${ }^{* *}$ \\ Juan Camilo Taborda Burgos ${ }^{* * *}$ \\ Juliana Vargas Gómez ${ }^{* * *}$
}

\section{SUMARIO}

Introducción - I. COMPOSICIÓN Y NATURALEZA DE LOS CTJT - II. FUNCIONES DE LOS CTJT - III. RETOS DE LOS CTJT - A. Retos externos a los CTJT - 1. Articulación del sistema de atención y reparación de las víctimas y el ciclo de planeación territorial - 1.1. Dos sistemas de planeación independientes - 1.2. Reflexiones sobre la articulación de los dos sistemas - 2. La aplicación diferencial de la política de atención y reparación para víctimas - 2.1. ¿Una verdadera aproximación diferencial en lo territorial? - 2.2. Problemas del índice de capacidades territoriales para la caracterización de EE. TT. 2.3. Reflexiones sobre el trato diferencial a las EE. TT. - 3. Retos frente a la articulación entre los cTJT y otras instancias del Estado que adelantan procesos administrativos y judiciales que también involucran a las víctimas del conflicto - $B$. Retos internos para los CTJT - 1. Frente a la participación de los representantes de las víctimas - 2. Frente a la interpretación de las normas que regulan el funcionamiento de los CTJT - IV. CONCLUSIONES - Referencias - Anexos.

* $\quad$ Cómo citar este artículo: Castrellón Pérez, M., Taborda Burgos, J. C. y Vargas Gómez, J. (Junio, 2015). Los retos de los comités territoriales de justicia transicional en la implementación de la Ley de Víctimas. Revista de Derecho Público, 34. Universidad de los Andes (Colombia).

\begin{abstract}
Este documento surge de reflexiones propias de los autores y de los aprendizajes derivados de la consultoría (Contrato n. ${ }^{\circ} 858 \mathrm{~S} 13-038$ ) desarrollada en 2013 por la Facultad de Derecho de la Universidad de los Andes para AECOM, que tuvo como objetivo: "diseñar una propuesta para orientar la operación de los 1112 comités de justicia transicional". Para ello se conformó un equipo interdisciplinario compuesto por abogados, historiadores y comunicadores, del que hicieron parte los autores de este documento; se desarrollaron cuatro guías temáticas (reparación colectiva, retornos y reubicaciones, medidas de satisfacción y garantías de no repetición) en las que se abordaron aspectos conceptuales y operativos; y se hicieron algunas visitas de campo (Cundinamarca, Barrancabermeja, Bucaramanga y Valledupar) para conocer de primera mano la realidad de los comités territoriales de justicia transicional (CTJT) y de sus integrantes. A continuación se menciona el equipo de la Facultad de Derecho que trabajó en esta, con el fin de reconocer los aportes que cada quien hizo tanto de manera individual como colectiva, a los aprendizajes conjuntos sobre los cTJT y a los productos finales: Helena Alviar, Delio Aparicio, Mariana Castrellón, Isabel Cristina Jaramillo, Natalia Ramírez, Esteban Restrepo, Santiago Rojas, Juan Camilo Taborda y Juliana Vargas. Algunos apartes de este artículo también fueron incluidos en los productos de la consultoría.
\end{abstract}

** Abogada y politóloga de la Universidad de los Andes. Actualmente es candidata a JSM en la Facultad de Derecho de la Universidad de Stanford. Correo: marianacastrellon@gmail.com

*** Abogado y politólogo de la Universidad de los Andes, con maestría en políticas públicas de la Hertie School of Governance de Berlín. Actualmente, como becario Fulbright, está adelantando estudios doctorales en el Fletcher School of Law and Diplomacy de Tufts University. Correo: jctaborda@gmail.com

**** Abogada de la Universidad de los Andes, con maestría en políticas públicas de la misma institución. Trabaja en la Fiscalía General de la Nación y ha sido consultora en el área de derechos humanos y políticas públicas. Correo: julianavargasg@gmail.com. 
Introducción ${ }^{1}$

La Ley de Víctimas y de Restitución de Tierras (Ley 1448 de 2011) fue sancionada el 10 de junio de 2011 con una vigencia de diez años. El objetivo principal de esta ley es hacer efectivo el goce de los derechos a la verdad, la justicia y la reparación integral de aquellas personas que han sufrido violaciones a sus derechos humanos e infracciones al derecho internacional humanitario en el marco del conflicto armado (arts. 1 y 3). Actualmente se registran más de 6 millones de víctimas del conflicto (Unidad de Víctimas, 2014) ${ }^{2}$ que, dependiendo de cada caso, tienen derecho a medidas de protección, atención, asistencias y reparación integral.

El alto número de víctimas y las medidas introducidas en esta ley generaron la necesidad de adecuar institucionalmente varias entidades estatales y de crear otras para prestar la atención requerida por las víctimas. En la práctica esto significó la creación de la Unidad para la Atención y Reparación Integral a las Víctimas (Unidad de Víctimas o UARIV), la Unidad Administrativa Especial de Gestión de Restitución de Tierras Despojadas (Unidad de Restitución de Tierras) y el Centro Nacional de Memoria Histórica (CNMH). Adicionalmente, otras entidades también responsables de la implementación de esta ley como el Ministerio de Salud, el Departamento

1 Una versión preliminar de este texto fue presentada en el Seminario Cijus "Los comités de justicia transicional y la reparación integral a las víctimas", realizado el 20 de marzo de 2014.

2 Disponible en: http://rni.unidadvictimas.gov.co/?q=node/107, consultado en julio 30/14. Ha pasado casi un año desde la presentación de este artículo a consideración de la Revista y el número actual de víctimas supera los 7 millones.
Nacional de Planeación y el Ministerio de Agricultura, entre otras tantas, se vieron obligadas a hacer adecuaciones internas de los planes de acción y presupuestos para garantizar la atención y reparación a las víctimas.

Esta adecuación no ha sido necesaria solo a nivel nacional, sino también a nivel territorial en el marco del Sistema Nacional de Atención y Reparación Integral a las Víctimas (sNARIV). Así, un número considerable de entidades públicas que antes venían atendiendo a la población víctima del desplazamiento forzado y de otros delitos ha tenido que ajustarse a las transformaciones demandadas por el nuevo marco normativo. ${ }^{3}$ Todo esto con el propósito de llegar efectivamente a las víctimas, quienes se encuentran en todas las regiones del país. ${ }^{4}$

La Ley de Víctimas señala en el artículo 174 las funciones que deberán cumplir las entidades territoriales (EE. тT.) en su implementación, e indica las fuentes presupuestales a las que deben acudir para cumplir este mandato:

1. Con cargo a los recursos del presupuesto departamental, municipal o distrital (...), deberán prestarles asistencia de urgencia, asistencia de gastos funerarios, complementar las medidas de atención y reparación integral y gestionar la presencia y respuesta oportuna de las autori-

3 El Sistema Nacional de Atención y Reparación Integral a las Víctimas (SNARIV) integra más de cincuenta entidades del nivel nacional, a todas las entidades territoriales y a la Mesa de Participación de Víctimas del respectivo nivel territorial (Ley de Víctimas, art. 160).

4 La postura del Gobierno Nacional sobre la paz territorial y su construcción en las regiones, bajo la vocería del Alto Comisionado para la Paz, guarda coherencia con este hecho (Jaramillo, 2014). 
dades nacionales respectivas para la atención, asistencia y reparación integral a las víctimas.

2. Con cargo a los recursos que reciban del Sistema General de Participaciones y con sujeción a las reglas constitucionales y legales correspondientes, garantizarles la prestación eficiente y oportuna de los servicios de salud, educación, agua potable y saneamiento básico.

3. (...) garantizar la seguridad y protección personal de las víctimas con el apoyo de la Policía Nacional de la cual deben disponer a través de los gobernadores y alcaldes como primeras autoridades de policía administrativa en los órdenes departamental, distrital y municipal. Para tal efecto, el Ministerio del Interior y de Justicia coordinará con las autoridades territoriales la implementación de estas medidas.

4. Elaborar y ejecutar los planes de acción para garantizar la aplicación y efectividad de las medidas de prevención, asistencia, atención y reparación integral a las víctimas en sus respectivos territorios, que respondan a los distintos hechos victimizantes generados por las violaciones contempladas en el artículo $3^{\circ}$ de la presente Ley.

Además de la asignación de estas funciones a las EE. TT., se crearon los comités territoriales de justicia transicional (стנт) como "la máxima instancia de coordinación, articulación y diseño de política pública en el departamento, municipio o distrito" (MinInterior, MinJusticia y UARIV, s.f., p. 7), sustituyendo a los antiguos comités territoriales para la atención integral a la población desplazada (Ley 387 de 1997, art. 7) y ampliando su población objetivo a las víctimas de todos los hechos victimizantes contemplados en la Ley de Víctimas. De acuerdo con el artículo 173 de la Ley de Víctimas, los cтJт están encargados de:

Elaborar los planes de acción en el marco de los planes de desarrollo a fin de lograr la atención, asistencia y reparación integral a las víctimas; coordinar las acciones con las entidades que conforman el Sistema Nacional de Atención y Reparación a las Víctimas en el nivel departamental, distrital y municipal; articular la oferta institucional para garantizar los derechos de las víctimas a la verdad, la justicia y la reparación, así como la materialización de las garantías de no repetición; coordinar las actividades en materia de inclusión social e inversión social para la población vulnerable; y adoptar las medidas conducentes a materializar la política, planes, programas y estrategias en materia de desarme, desmovilización y reintegración.

De acuerdo con lo establecido en el artículo 252 del Decreto 4800 del 2011 su propósito es reunir a las entidades del nivel municipal, distrital y departamental competentes, así como a los representantes de las víctimas, para coordinar, articular y evaluar acciones, proyectos y programas que tengan como objetivo la atención y reparación de la población víctima, en sus respectivos territorios.

Sin embargo, su operatividad no parece tan sencilla y en lo corrido de la implementación de la Ley de Víctimas han tenido una serie de dificultades que les han restado eficiencia en su gestión como instancias de decisión. En esta medida, el propósito principal de este artículo es identificar los principales retos de los стנт en la implementación de la Ley de Víctimas, atendiendo a sus funciones, su composición y sus 
procedimientos. Para alcanzar este objetivo, en primer lugar se describirá con más detalle su composición, su naturaleza y sus funciones, con el fin de comprenderlos mejor y poder aproximarnos con más exactitud a los retos que estos enfrentan en su quehacer cotidiano. En segundo lugar, se describirán los retos identificados, los cuales se sitúan en dos niveles: uno que hemos denominado "externo" y hace alusión a los retos que están por fuera de los стJ pero que tienen impacto en su funcionamiento; otro que hemos llamado "interno" y está referido a los retos que debido a la naturaleza misma de los CTJT se presentan. Por último, se expondrán unas conclusiones preliminares sobre el rol de los cTJT en la implementación de la Ley de Víctimas y los retos que enfrentan para el cumplimiento de su labor.

\section{COMPOSICIÓN Y NATURALEZA DE LOS CTJT}

Como se señaló anteriormente, los cтJT se crean como la máxima instancia de articulación a nivel territorial de la Ley de Víctimas (D. 4800/11, art. 250). En ellos se reúnen miembros de entidades del orden nacional, territorial, entes de control, fuerza pública y sociedad civil. De acuerdo con el artículo 173 de la Ley de Víctimas, la composición de los стנт es la siguiente:

1. El Gobernador o el alcalde, quien lo presidirá, según el caso. ${ }^{5}$

5 Los gobernadores presidirán los CTJT departamentales y los alcaldes los CTJT municipales.
2. El Secretario de Gobierno departamental o municipal, según el caso.

3. El Secretario de Planeación departamental o municipal, según el caso.

4. El Secretario de Salud departamental o municipal, según el caso.

5. El Secretario de Educación departamental o municipal, según el caso.

6. El Comandante de División o el Comandante de Brigada, que tenga jurisdicción en la zona.

7. El Comandante de la Policía Nacional en la respectiva jurisdicción.

8. El Director Regional o Coordinador del Centro Zonal del Instituto Colombiano de Bienestar Familiar (ICBF).

9. El Director Regional del Servicio Nacional de Aprendizaje (sena).

10.Un representante del Ministerio Público.

11. Dos representantes de las Mesas de Participación de Víctimas de acuerdo con el nivel territorial.6

12. Un delegado del Director de la Unidad Administrativa Especial de Atención y Reparación Integral a las Víctimas.

Los integrantes de los стנт no pueden delegar su asistencia, lo cual en algunos casos puede generar dificultades para reunir al Comité dado el alto nivel jerárquico de los funcionarios que lo

6 Cada representante tiene un voto. 
conforman, sus apretadas agendas de trabajo y la gran cantidad de comités sectoriales a los que deben asistir, adicionales al cтJ. ${ }^{7}$

Además de las entidades antes mencionadas y de los representantes de las víctimas, los alcaldes y gobernadores pueden convocar a otras entidades y organizaciones adicionales para que hagan parte del cтJ (Ley de Víctimas, art. 173, párr. 1). Por ejemplo, el cтJ de Cundinamarca cuenta con la presencia de veinte entidades (D. $138 / 2012$, art. 1) y el de Barrancabermeja con catorce (D. 033/12, art. 3). ${ }^{8}$

Respecto de esta composición es importante llamar la atención sobre algunos asuntos en particular. En primer lugar, aunque la naturaleza del CTJT no es netamente administrativa puesto que tiene una composición heterogénea de la que hacen parte miembros del Ministerio Público, la fuerza pública y la sociedad civil, es presidido por el gobernador o alcalde, respectivamente. En principio esto no representa ninguna dificultad, sin embargo, a pesar de que la Ley de Víctimas guarda silencio respecto de cómo se deben tomar las decisiones (consenso o mayorías), los

7 En el trabajo de campo realizado en desarrollo de la consultoría, el secretario de Planeación de una entidad territorial nos informó que además del CTJT debía asistir a otros 32 comités técnicos sectoriales y coordinar la formulación de diez programas.

8 El CTJT de Cundinamarca cuenta también con la participación de los secretarios de Desarrollo Social, Agricultura, Competitividad y Desarrollo Económico; el director de la Unidad de Vivienda; el gerente de la Beneficencia del departamento; un representante adicional del Ministerio Público (asiste al CTJT tanto el defensor regional del Pueblo como el procurador regional de Cundinamarca) y los directores regionales del Departamento para la Prosperidad Social (DPS) y del Instituto Colombiano de Desarrollo Rural (INCODER). En el caso del CTJT de Barrancabermeja, además de los miembros listados en el art. 173 de la Ley de Víctimas, asiste también el director regional del INCODER. decretos de creación de algunos ctJt, revisados en el marco de esta investigación, indican que es por consenso, lo cual puede tener ventajas y desventajas. La principal ventaja es que los representantes de las víctimas están en capacidad de vetar iniciativas que no les beneficien; la desventaja es que, justamente, debido a la naturaleza heterogénea del Comité, llegar a acuerdos puede ser sumamente difícil por los diferentes intereses y posiciones que allí concurren.

En segundo lugar, la composición de los comités puede presentar dificultades pues reúne en un mismo espacio miembros entre los cuales puede haber relaciones de desconfianza o prevenciones, como por ejemplo, víctimas-fuerza pública; víctimas-secretarías (en un sentido más abstracto: víctimas-Estado) e instituciones administrativas-Ministerio Público. Respeto del primero (víctimas-fuerza pública), la ruptura de la relación de confianza entre las partes puede ilustrarse claramente en dos casos que han sido recurrentes en el conflicto armado colombiano. El primero son los llamados "falsos positivos" que han sido documentados por diferentes organizaciones, y frente a los cuales actualmente la Fiscalía ha generado más de 180 condenas (Human Rights Watch, 2014, p. 4). El segundo son los abusos y violaciones sexuales cometidas por los miembros de la fuerza pública hacia las mujeres (ABColombia, Sisma Mujer y U.S. Office on Colombia, 2013).

Más aún, en escenarios de conflicto armado, como en el caso colombiano, el Estado no ha logrado mantenerse neutral ante la población civil, generando violaciones como un actor más 
del conflicto. ${ }^{9}$ En esta medida, la reunión de actores con tales antecedentes puede ser sumamente compleja. El Centro Internacional para la Justicia Transicional (ICTJ por sus siglas en inglés) y el Programa de Naciones Unidas para el Desarrollo (PNUD) han afirmado que "luego de un pasado de violaciones graves de los derechos humanos y de infracciones al Derecho Internacional Humanitario, la confianza de la ciudadanía en sus instituciones se resquebraja $y$, en muchos casos, desaparece" (ICTJ y PNUD, 2011, p. 5).

Ahora bien, a pesar de que los miembros que toman asiento en el Comité no han sido necesariamente victimarios, existe una tensión que se deriva de los hechos antes descritos y de la historia misma del conflicto armado. Además de lo anterior, diferentes estudios han demostrado que a pesar del planteamiento general de que el Estado busca el bienestar de los ciudadanos, los servidores públicos y los políticos que han sido elegidos y designados son actores que tienen intereses propios y la arena política es el escenario donde se juegan esos intereses (Ostrom, 1973, p. 114; Arellano, 2007, p. 96). Estos intereses, que en muchas ocasiones tienen la potencialidad de ir en contra de la ciudadanía, pueden ocasionar la ruptura de la confianza que se busca construir entre esta y las instituciones públicas. Por ejemplo, es probable que los intereses del gobernador o del alcalde que

9 Así lo evidencian las condenas en contra del Estado colombiano por parte de la Corte Interamericana de Derechos Humanos en los casos: Masacre de Santo Domingo vs. Colombia; Manuel Cepeda Vargas vs. Colombia; Masacre de La Rochela vs. Colombia; Masacre de Pueblo Bello vs. Colombia; Masacres de Ituango vs. Colombia y Masacre de Mapiripán vs. Colombia. preside el Comité apunten principalmente al cumplimiento del Plan de Desarrollo, y en aras de lograr ese objetivo hagan uso del Comité sin que necesariamente se tomen medidas especiales para las víctimas. Por otra parte, existe la posibilidad de que los miembros de la fuerza pública tengan poco interés en hacer parte de la construcción de la memoria histórica como una medida de satisfacción, pues pueden verse implicados de alguna manera.

En tercer lugar, este espacio se concibe como una instancia en la que se reúnen los miembros llamados a conformar el Comité, para tomar decisiones que les permitan implementar los mandatos de la Ley de Víctimas. En esta medida, el CTJT no es en sí mismo un cuerpo autónomo, con un presupuesto propio para ejecutar en favor de la implementación de la mencionada ley, sino la reunión de unos funcionarios públicos (varios de ellos con una cartera a cargo, un presupuesto y metas propias) y de miembros de la sociedad civil que deben tomar una serie de decisiones para avanzar en la implementación de la Ley de Víctimas.

Por último, los funcionarios públicos que participan en el CтJT tienen que cumplir funciones respecto de la Ley de Víctimas tanto en virtud de su cargo como en calidad de miembros del Comité y no hay claridad sobre qué actos deben llevar a cabo en una u otra condición. Por ejemplo, el secretario de Educación debe asegurar los cupos a los niños y niñas víctimas desde la Secretaría a su cargo y con el presupuesto a ella asignado, mientras funge a la vez como miembro del cTJT. 
Cómo advierten Cameron y Green (2004) para instituciones similares, la vaguedad en la responsabilidad de cada uno de los miembros del Comité y en los objetivos mismos del grupo de trabajo deviene en dificultad para el adecuado funcionamiento de estas estructuras y el logro de sus objetivos. Lo anterior es particularmente cierto en un ambiente tan reglado y jerarquizado como el sector público, pues los actores suelen determinar su comportamiento y enfocarse en las tareas específicas de sus funciones y no en las tareas abstractas de responsabilidad compartida en cabeza de un grupo o equipo de trabajo semiestructurado, como sería el caso de los cTJT.

\section{FUNCIONES DE LOS CTJT}

Como se señaló en la introducción, cada alcalde y gobernador tiene la obligación de conformar el Comité Territorial de Justicia Transicional de su respectivo ente territorial (D. 4800/11, art. 253, num. 1). Con esta estructura y liderazgo, los CTJT se conciben como instancias de decisión y monitoreo. Es por esto que, de manera complementaria a la estructura de los cTJT, se han creado los subcomités, como instancias donde se desarrolla el trabajo técnico para la implementación de la Ley de Víctimas. En ellos participan funcionarios de las entidades competentes, que se determinan dependiendo de la temática que desarrolle cada subcomité, por ejemplo: prevención y protección, atención y asistencia, y reparación integral. A estos subcomités también asisten representantes de las víctimas.
Ahora bien, respecto a las herramientas de planeación, de acuerdo con el Decreto 4800 de 2011 los gobernadores y alcaldes, respectivamente, deben diseñar e implementar el plan de acción departamental (art. 250, num. 5) o municipal (art. 251, num. 4), conocidos de manera genérica como planes de acción territorial (PAT). Aunque la ley establece esta competencia en cabeza de los gobernadores y alcaldes, el стJT juega un rol fundamental en este proceso pues debe aprobar el respectivo PAT. LOS PAT Son la ruta de acción que deben seguir los cтנт para la implementación de la Ley de Víctimas, pues en los entes territoriales deben contemplar y planear las medidas de prevención, atención, asistencia y reparación integral a las víctimas del conflic-

to armado. Estos planes tienen una vigencia de cuatro años, la cual debe coincidir con los periodos de los mandatos locales. En esta medida, los PAT deben ser coherentes con los planes de desarrollo territorial ${ }^{10}$ y con el Plan Nacional de Atención y Reparación a Víctimas (anexo del Conpes 3726 de 2012).

A pesar del mandato general de la elaboración y contenidos mínimos de los PAT para las EE. TT., es importante destacar que la Ley de Víctimas reconoce la heterogeneidad en sus capacidades y necesidades. Por esto, el Decreto 4800 de 2011 define que al momento de efectuar el diseño de la estrategia de articulación de la oferta pública en materia de ayuda humanitaria, atención, asistencia y reparación integral entre los distintos niveles territoriales, esta se debe construir

10 Ley de Víctimas, art. 174; Decreto 4800 de 2011, art. 254; Minlnterior, MinJusticia y UARIV (s.f. p. 7). 
teniendo en cuenta las dinámicas locales y las condiciones diferenciales de cada entidad territorial, tales como su capacidad fiscal, su índice de necesidades básicas insatisfechas, su índice de presión y las necesidades del ente territorial en relación con la atención a víctimas.

Adicionalmente, el Plan Nacional de Atención y Reparación a Víctimas reconoce que uno de los principales desafíos en el proceso de implementación de esta ley es la articulación de las políticas públicas en los distintos niveles territoriales. Para lograr dicha articulación, señala que es fundamental definir las competencias y responsabilidades de las entidades territoriales partiendo del reconocimiento de la heterogeneidad de los municipios y departamentos, relacionada con sus capacidades fiscales, administrativas y financieras. ${ }^{11}$

Es por esto que los cTJT deben realizar un ejercicio que les permita identificar sus fortalezas y debilidades, y con base en estas programar y planificar las acciones relacionadas con la implementación de la Ley de Víctimas. Esto, sumado a la responsabilidad que se otorgó a la Unidad de Víctimas y al Departamento Nacional de Planeación (DNP) en la creación de un índice de capacidad territorial para diferenciar a las EE. тт. Todo lo anterior para que, en caso de ser necesario, se haga uso de los principios de concurrencia, coordinación y subsidiariedad, de modo que los obstáculos que se presenten a nivel territorial no se vuelvan infranqueables para la materialización de los derechos de las víctimas en Colombia (Ley de Víctimas, art. 172).

A continuación se presentan las funciones generales de los стנт de acuerdo con el artículo 252 del Decreto 4800 de 2011, agrupadas en los siguientes tipos: 1) Coordinación, articulación y diseño; 2) Adopción y desarrollo de medidas y estrategias; y 3) Seguimiento y evaluación.

11 A pesar de lo anterior, más adelante se demostrará cómo este reconocimiento a la heterogeneidad es formal, pues en la práctica la implementación de esta ley en las diferentes EE. TT. no está sucediendo así. 
Cuadro 1. Funciones generales de los CTJT

\begin{tabular}{|c|c|c|}
\hline Tipo de función & Responsabilidades del Comité Territorial de Justicia Transicional & $\begin{array}{l}\text { Referencias reglamen- } \\
\text { tarias }\end{array}$ \\
\hline $\begin{array}{l}\text { Coordinación, } \\
\text { articulación y } \\
\text { diseño }\end{array}$ & $\begin{array}{l}\text { - Servir de instancia de articulación para la elaboración de los planes } \\
\text { de acción para el cumplimiento de los objetivos y metas de los planes } \\
\text { de desarrollo territoriales en cumplimiento de la Ley } 1448 \text { de } 2011 \text {, a } \\
\text { fin de lograr la prevención, atención, asistencia y reparación integral } \\
\text { a las víctimas. } \\
\text { - Coordinar las acciones con las entidades que conforman el Sistema } \\
\text { Nacional de Atención y Reparación Integral a las Víctimas en el nivel } \\
\text { departamental, municipal o distrital. } \\
\text { - Articular la oferta institucional para garantizar los derechos de las víc- } \\
\text { timas a la verdad, justicia y reparación, así como la materialización de } \\
\text { las garantías de no repetición. } \\
\text { - Coordinar las actividades en materia de inclusión social e inversión } \\
\text { social para la población víctima. }\end{array}$ & $\begin{array}{l}\text { Decreto } 4800 \text { de } 2011 \text {, } \\
\text { art. } 252 \text {, nums. 1, 2, } 3 \text { y } 4 .\end{array}$ \\
\hline $\begin{array}{l}\text { Adopción y de- } \\
\text { sarrollo de medi- } \\
\text { das y estrategias }\end{array}$ & $\begin{array}{l}\text { - Adoptar las medidas conducentes a materializar la política, planes, } \\
\text { programas, proyectos y estrategias en materia de desarme, desmovili- } \\
\text { zación y reintegración. } \\
\text { - Adoptar las estrategias que se requieran para garantizar la partici- } \\
\text { pación de las víctimas en la formulación, ejecución, seguimiento y } \\
\text { evaluación del plan de acción territorial de asistencia, atención y repa- } \\
\text { ración integral a las víctimas. } \\
\text { - Desarrollar estrategias de prevención integral para lo cual coordinará } \\
\text { con los comités territoriales de prevención. }\end{array}$ & $\begin{array}{l}\text { Decreto } 4800 \text { de } 2011 \text {, } \\
\text { art. } 252 \text {, nums. 5, } 9 \text { y } 10 .\end{array}$ \\
\hline $\begin{array}{l}\text { Seguimiento y } \\
\text { evaluación }\end{array}$ & $\begin{array}{l}\text { - Preparar informes sobre las acciones que se han emprendido y su } \\
\text { resultado, los recursos disponibles y los solicitados a otras autoridades } \\
\text { locales, regionales y nacionales, sobre las necesidades de formación } \\
\text { y capacitación del personal que ejecutará las medidas de prevención, } \\
\text { asistencia, atención y reparación integral a las víctimas. } \\
\text { - Garantizar que las políticas, planes, programas y proyectos encami- } \\
\text { nados hacia la prevención, asistencia, atención y reparación integral } \\
\text { a las víctimas, incorporen medidas que respondan a las necesidades } \\
\text { particulares de los sujetos de especial protección constitucional o que } \\
\text { se encuentren en mayor grado de vulnerabilidad. } \\
\text { - Diseñar un mecanismo de evaluación periódica que permita hacer los } \\
\text { ajustes necesarios a la ejecución del plan de acción territorial de asis- } \\
\text { tencia, atención y reparación integral a las víctimas, teniendo en cuenta } \\
\text { los avances en el cumplimiento de las metas de corto, mediano y largo } \\
\text { plazo. }\end{array}$ & $\begin{array}{l}\text { Decreto } 4800 \text { de } 2011 \text {, } \\
\text { art. } 252 \text {, nums. } 6 \text { y } 7 .\end{array}$ \\
\hline
\end{tabular}

Fuente: elaboración propia con base en la Ley de Víctimas y el Decreto 4800 de 2011. 
Como se desprende del anterior cuadro y de lo ya descrito, la naturaleza de las funciones generales de los стנт es de articulación y coordinación. Estas funciones son de difícil aplicación por tratarse de obligaciones de medio que son abstractas. Al no tener determinado un cómo, quién, cuándo y dónde en la Ley de Víctimas y sus decretos reglamentarios, tienden a desdibujarse y su ejecución es sumamente compleja.

Respecto de la función de coordinar, los CTJT deben asegurar la confluencia de un significativo número de funcionarios públicos y víctimas. Como se indicó antes, tienen un mínimo de trece miembros, que pueden aumentar dependiendo de cada caso; deben coordinar las acciones, planes y programas de las entidades que se relacionan con la atención a víctimas para lograr brindarles un servicio integral y dignificante; y deben crear canales de comunicación y espacios de discusión para adelantar las acciones que materialicen la atención y reparación a las víctimas.
Adicionalmente, la articulacin y desarrollo de medidas parte de lo acordado en la Plan de Accipoinspacios de reunita institucional que garantice los derechosón que deben gestionar los CтJт es indispensable para organizar la oferta institucional en cada uno de los territorios y activar los principios de coordinación, concurrencia y subsidiariedad cuando a nivel territorial no se disponga de la oferta institucional ni de los recursos necesarios para garantizar los derechos de las víctimas.

Además de estas funciones, los cTJ tienen otras específicas relacionadas con los componentes de la política pública de víctimas. Dentro de estas, es posible encontrar vacíos y contradicciones que generan dificultades (o retos) adicionales para los стנт en la implementación de la ley. Estos retos se explicarán en detalle en la segunda parte de este artículo. 


\begin{tabular}{|c|c|c|}
\hline $\begin{array}{r}\text { Compon } \\
\text { med }\end{array}$ & Responsabilidades del Comité Territorial de Justicia Transicional. & $\begin{array}{l}\text { Referencias reglamenta- } \\
\text { rias }\end{array}$ \\
\hline $\begin{array}{l}\text { Asistencia y aten- } \\
\text { ción }\end{array}$ & $\begin{array}{l}\text { - Valorar la cesación de la condición de desplazamiento forzado por } \\
\text { parte de la Unidad de Víctimas en el marco del CTJT. } \\
\text { - Realizar seguimiento a las asignaciones fiscales de las entidades } \\
\text { competentes en el cumplimiento de la asistencia funeraria. }\end{array}$ & $\begin{array}{l}\text { - Decreto } 4800 \text { de 2011, } \\
\text { arts. } 81 \text { y } 100 .\end{array}$ \\
\hline $\begin{array}{l}\text { Reparación integral } \\
\text { colectiva }\end{array}$ & - Aprobar los planes de reparación colectiva. & $\begin{array}{l}\text { - Decreto } 4800 \text { de 2011, } \\
\text { art. } 230 .\end{array}$ \\
\hline $\begin{array}{l}\text { Restitución de } \\
\text { tierras }\end{array}$ & $\begin{array}{l}\text { - Articularse con el Subcomité de Restitución de Tierras para definir } \\
\text { las medidas de seguridad. }\end{array}$ & $\begin{array}{l}\text { - Decreto } 4829 \text { de } 2011 . \\
\text { - Documento CONPES } 3726 \text {, } \\
\text { pp. } 36 \text { y } 38 .\end{array}$ \\
\hline Indemnización & $\begin{array}{l}\text { - Participar en la ejecución del Programa de acompañamiento para } \\
\text { la inversión adecuada de los recursos. }\end{array}$ & $\begin{array}{l}\text { - Decreto } 4800 \text { del 2011, } \\
\text { art. } 158 .\end{array}$ \\
\hline $\begin{array}{l}\text { Medidas de satis- } \\
\text { facción y repara- } \\
\text { ción simbólica }\end{array}$ & $\begin{array}{l}\text { - Definir los criterios para la concertación entre las víctimas y la } \\
\text { UARIV para la realización de las medidas de satisfacción (para la } \\
\text { elaboración de estos criterios, los CTJT recibirán asistencia técnica } \\
\text { de la UARIV). } \\
\text { - Hacer seguimiento a la implementación de las medidas de satis- } \\
\text { facción en su municipio, distrito o departamento. } \\
\text { - Establecer fechas para honrar a las víctimas y realizar eventos so- } \\
\text { bre memoria histórica y solidaridad con ellas. }\end{array}$ & $\begin{array}{l}\text { - Decreto } 4800 \text { del } 2011 \text {, } \\
\text { arts. } 171,172 \text { y } 185 . \\
\text { - Documento CONPES } 3726 \text {, } \\
\text { pp. } 65,66 \text { y } 67 .\end{array}$ \\
\hline $\begin{array}{l}\text { Prevención y pro- } \\
\text { tección }\end{array}$ & $\begin{array}{l}\text { - Concertar con alcaldes y gobernadores los planes integrales de } \\
\text { prevención y planes de contingencia. } \\
\text { - Determinar medidas de prevención y protección. } \\
\text { - Elaborar y poner en marcha los planes de contingencia para at- } \\
\text { ender las emergencias producidas en el marco del conflicto armado. } \\
\text { - Actualizar los planes de contingencia. }\end{array}$ & $\begin{array}{l}\text { - Decreto } 4800 \text { de 2011, } \\
\text { arts. } 202 \text { y } 203 .\end{array}$ \\
\hline $\begin{array}{l}\text { Retornos y reubi- } \\
\text { caciones }\end{array}$ & $\begin{array}{l}\text { - Adoptar acciones de coordinación, planeación, seguimiento y par- } \\
\text { ticipación de víctimas incluidas en los procesos de retorno o reubi- } \\
\text { cación. } \\
\text { - Elaboración y aprobación de los planes de retornos y reubicacio- } \\
\text { nes masivas. } \\
\text { - Evaluar las condiciones de seguridad en operaciones de retornos y } \\
\text { reubicaciones emitidas por la Fuerza Pública. }\end{array}$ & $\begin{array}{l}\text { - Decreto } 4800 \text { de } 2011 \text {, } \\
\text { arts. } 76,78 \text { y } 219 . \\
\text { - Documento CONPES } 3726 \text {, } \\
\text { p. } 32 . \\
\text { - Anexo documento CONPES } \\
3726 \text { pp. } 125 \text { a } 129 .\end{array}$ \\
\hline Participación & - Generar un espacio de participación de las víctimas. & $\begin{array}{l}\text { - Decreto } 4800 \text { del 2011, } \\
\text { art. } 263 .\end{array}$ \\
\hline $\begin{array}{l}\text { Registro y Red } \\
\text { Nacional de Infor- } \\
\text { mación }\end{array}$ & $\begin{array}{l}\text { - Contribuir a la elaboración de un censo en caso de hechos victim- } \\
\text { izantes masivos (la UARIV podrá, cuando lo estime necesario, so- } \\
\text { licitar al CTJT información relevante para el proceso de verificación). }\end{array}$ & $\begin{array}{l}\text { - Decreto } 4800 \text { del 2011, } \\
\text { art. } 46 .\end{array}$ \\
\hline
\end{tabular}

Fuente: elaboración propia con base en la Ley de Víctimas y el Decreto 4800 de 2011. 


\section{RETOS DE LOS CTJT}

Como se señaló en la introducción, en el desarrollo de este trabajo se encontraron dos tipos de retos. Los retos externos a los стJ, que han sido identificados como: (1) Articulación del SNARIv y el ciclo de planeación; (2) Aplicación diferencial de la política de atención y reparación a las víctimas y (3) Articulación entre los cтנт y otras instancias del Estado que adelantan procesos administrativos y judiciales que también involucran a las víctimas del conflicto. Además de estos, se encuentran los retos internos, que han sido identificados de la siguiente forma: (1) Frente a la participación de los representantes de las víctimas y (2) Frente a la interpretación de las normas que regulan el funcionamiento de los CTJT.

\section{A. Retos externos a los CTJT}

\section{Frente a la articulación del SNARIV y el ciclo de planeación territorial}

Como se identificó en la sección anterior, la articulación es una de las funciones principales de los стлt. Para lograrla deben adecuarse a los ciclos generales de la gestión pública territorial y a los ciclos e instrumentos de planeación de las EE. TT. Esta articulación entre instrumentos y ciclos de planeación es fundamental para que las acciones determinadas por los стJ se materialicen en las políticas, programas y proyectos que contribuyan a la atención y reparación de las víctimas.
Para explicar en qué consiste el reto de la articulación de los sistemas -el Sistema Nacional de Atención y Reparación Integral a las Víctimas y el Sistema Nacional de Planeación-, esta sección iniciará explicando por qué se conciben, en efecto, como dos sistemas independientes. Posteriormente, se explicará cómo la creación de este sistema paralelo para la atención de víctimas puede generar mayores cargas en la administración de las EE. TT. Finalmente, se señalará cómo la falta de coordinación entre los instrumentos legales de la Ley de Víctimas frente a las normas que regulan el ciclo de planeación y presupuesto aumentan la dificultad de articular estos dos sistemas de planeación.

\subsection{Dos sistemas de planeación independientes}

Las EE. TT. realizan su planeación estratégica y presupuestal con base en el Sistema General de Planeación, reglado principalmente por la Ley 152 de 1994. Este sistema determina la manera en que las entidades públicas establecen sus políticas y estrategias para alcanzar el desarrollo integral, cómo financiarlas con base en el ciclo presupuestal, así como instrumentos y términos claramente establecidos.

No obstante lo anterior, la Ley de Víctimas creó, de hecho, un sistema paralelo de planificación territorial para la atención y reparación a las víctimas, que gira en torno a los PAT, instrumento que se espera posibilite la articulación con el ciclo de planeación de las EE. TT. que se regula por la Ley 152 de 1994. Por ello, los artículos 254 y 255 del Decreto 4800 de 2011 y el 174 de la Ley de Víctimas señalan: 
LOS PAT contemplan las medidas de prevención, atención, asistencia y reparación integral a las víctimas del conflicto armado, los cuales deben ser elaborados por los departamentos, municipios y distritos para una vigencia de cuatro años en concordancia con los periodos de los mandatarios locales, y deben guardar coherencia con el Plan Nacional de Atención a Víctimas y los Planes de Desarrollo Territorial (MinInterior, Minjusticia, Minhacienda, DNP y UARIv, 2012, p. 7).

Como ya se explicó, el PAT es un instrumento que debe ser diseñado por la entidad territorial con la participación de las víctimas y aprobado por los стנт, articulándose con el Plan Nacional de Atención y Reparación Integral de las Víctimas y con los Planes de Desarrollo Territoriales. Además, el PAT consolida múltiples instrumentos y estructura la planeación estratégica de la atención y reparación a las víctimas. Así pues, el PAT es el instrumento que determina la manera en que los municipios y departamentos del país generarán estrategias para la atención y reparación de las víctimas; por ello es fundamental la injerencia de los cтJ que son, finalmente, quienes dan el visto bueno al conjunto de programas, políticas y proyectos contenidos en el PAT.

Si bien el PAT tiene una vigencia de cuatro años, anualmente, es decir, en cada vigencia fiscal, deberá ser modificado para incluir la oferta programática en materia de prevención, asistencia, atención y reparación integral a las víctimas. Así mismo, con base en la Guía para su formulación y ajuste debe incluir el Plan Integral Único (PIU) para la atención de la población desplazada que se encuentre aún vigente (MinInterior et al., 2012, pp. 15-17).
Para asegurar la implementación del PAT, este debe articularse no solo con el proceso de planeación y gestión pública de las entidades territoriales, sino alinearse con los instrumentos que se presentan en el gráfico 1 , de modo que se asegure la integralidad del proceso de planificación territorial. Además, debe articular otros instrumentos de planeación propios de la Ley de Víctimas o relacionados con el SNARIV.

Gráfico 1. PAT como eje del sistema de planeación de laatención y reparación de las víctimas

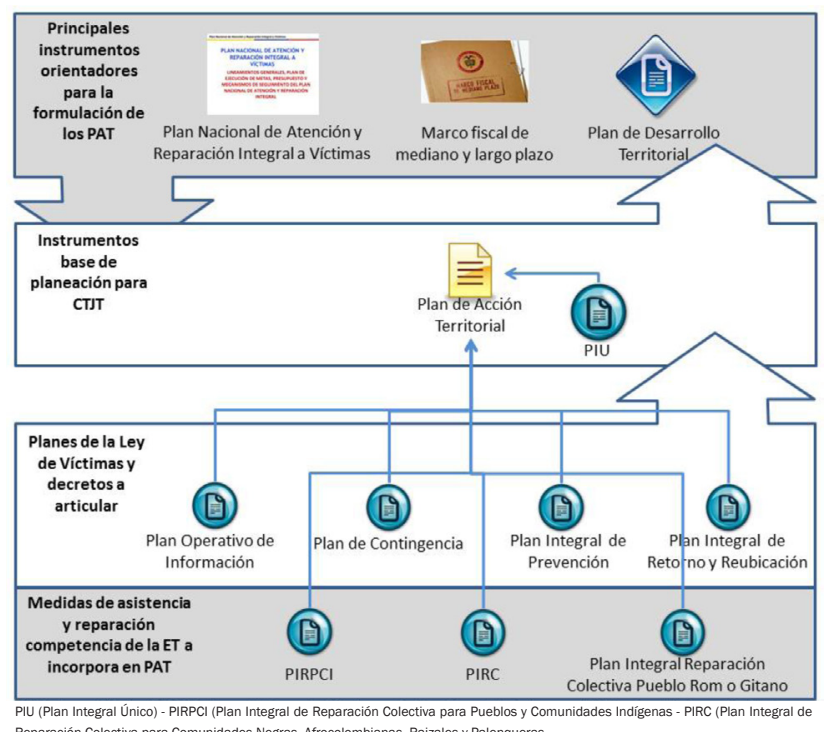

Fuente: elaboración propia con base en MinInterior et al., (2012).

Por otra parte, el ciclo de planeación y apropiación presupuestal de las EE. TT. se compone fundamentalmente de dos tipos de instrumentos, unos determinantes en el momento de la planeación de las políticas públicas y otros ligados a la distribución y ejecución presupuestal. Los fundamentales en el momento de la planeación son: el Plan de Desarrollo Territorial (PDT), el marco fiscal de mediano y largo plazo y la visión estratégica. 
Por su parte, los instrumentos fundamentales para la ejecución del presupuesto son: el Plan Indicativo, el Plan Operativo Anual de Inversiones (POAI), el Presupuesto Anual, el Plan de Acción y el Programa Anual Mensualizado de Caja (PAC).

Cada uno de estos instrumentos funciona en el marco del proceso de planeación y llena de contenido a los que le anteceden. De este modo, tal como se ilustra en el gráfico 2, el marco fiscal de mediano y largo plazo y la visión estratégica generan los insumos con los cuales se elabora el PDT. A su vez, este instrumento contiene los objetivos y estrategias que se concretan en el Plan Indicativo, que se desarrolla a través del PoAl y el Presupuesto Anual. Finalmente, el Presupuesto Anual se materializa a través del Plan de Acción Anual y el PAC.

Los instrumentos de la planeación son el marco para este aspecto en todo el periodo de gobierno, y por ello son determinantes para la ejecución de los programas y proyectos de las EE. TT., incluidos los que van dirigidos a la atención y reparación de las víctimas.
Gráfico 2. Encadenamiento de instrumentos deplaneación

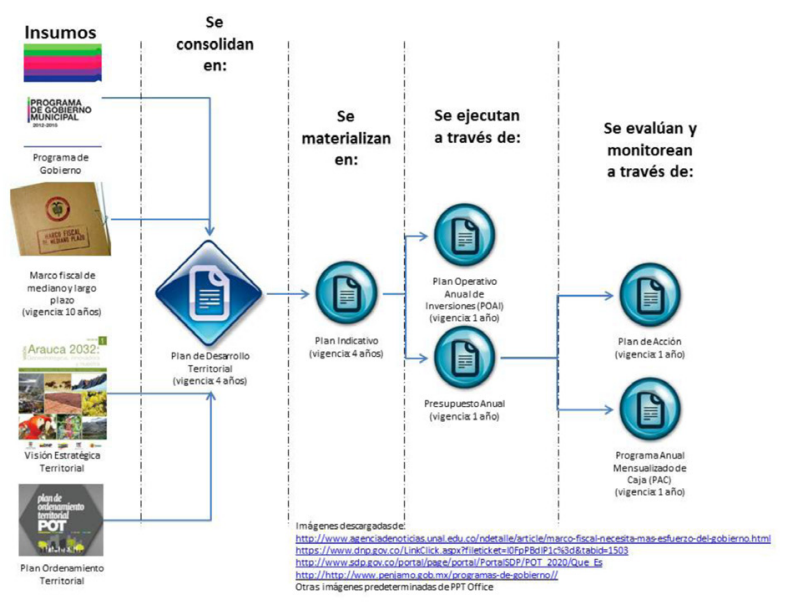

Fuente: elaboración propia con base en DNP (2012a y 2012b).

Por su parte, los instrumentos de ejecución, que suelen tener una vigencia anual, determinan y especifican los detalles para la asignación de recursos a las políticas, programas y proyectos, y son relevantes para evaluar el cumplimiento de estas por cuanto las materializan en acciones tangibles para la población objetivo, permitiendo establecer indicadores de resultado, como se muestra en el gráfico 3 que aparece en los anexos.

La anterior descripción de los instrumentos más relevantes del sistema de planeación de las EE. TT. y del sistema de planeación de la atención y reparación a las víctimas, evidencia que en efecto se trata de dos sistemas paralelos de planeación que deben estar articulados. En el recuadro 1 se presenta un ejemplo hipotético de cómo debería darse la articulación. 


\section{Recuadro 1. La articulación de sistemas: un ejemplo ideal}

EI CTJT de un municipio colombiano ha realizado la caracterización de sus víctimas en el PAT. Ha identificado que estas tienen bajos niveles en la formación técnica requerida, por ejemplo, para trabajar en proyectos agroindustrales, y adicionalmente ha constatado que no se han podido incorporar al mercado laboral formal. Con base en este diagnóstico se plantea que una estrategia para la reparación de las víctimas, puede ser asegurar su acceso prioritario a los programas de formación de capital humano del municipio.

Por su parte, el diagnóstico del PDT de la ET indica que el sector agroindustrial será el motor de la dinámica económica del municipio y que existen déficits en la oferta de trabajadores con esta formación técnica. Por tal razón, se requiere iniciar un programa de formación de capital humano que responda a estas necesidades.

Con base en los dos diagnósticos, tanto en el PAT como en el PDT se incluye una línea estratégica que consiste en asegurar el acceso prioritario de las víctimas en los programas de formación técnica para el sector agroindustrial. La meta contenida en el PDT aclara cuántos cupos se deben asegurar para las víctimas, y el Plan Indicativo desagrega las metas anuales de cobertura para el programa. Adicionalmente, los recursos requeridos para ejecutar el programa quedan presupuestados en el POAl y en el Presupuesto anual. De igual manera, en el Plan Anual de Acción del municipio y en su PAC se especifican las actividades para desarrollar el programa y ejecutar los recursos.

Durante el segundo año de gobierno, el CTJT revisa la ejecución del presupuesto y el PAC del municipio y corrobora el avance en las metas del programa en lo referente a los cupos para las víctimas, para todo el periodo de gobierno. Revisa el cumplimiento satisfac- torio de las metas de la primera vigencia contenidas en el Plan Indicativo y en el Plan de Acción del municipio. Con base en la evaluación de estos instrumentos se actualiza el PAT y se adecua la línea estratégica contenida en el instrumento

\subsection{Reflexiones sobre la articulación de los dos sistemas}

Al respecto, lo primero que se debe señalar es que estos dos ciclos de planeación se deberían articular, pero no parecen existir incentivos para que esto se produzca en la práctica. Por el contrario, lo que se observa es que el sistema de planeación derivado de la Ley de Víctimas obliga a las EE. TT. a implementar nuevos instrumentos de planificación, en vez de incorporarlos como un tema transversal de la planificación territorial, por lo menos en las acciones que tienen que ver con educación, salud, vivienda, saneamiento básico, agua potable, entre otros, para no derivar en un problema similar a lo que se observa hoy con el sector ambiental (ver recuadro 2).

\section{Recuadro 2. El sistema paralelo del sector ambiental}

A partir de la expedición de la Ley 99 de 1993, este sector ha avanzado en el posicionamiento de temas que son fundamentales para el uso sostenible de los recursos naturales, tales como: el manejo de zonas ambientales especiales, de zonas de protección especial y de rondas y cuencas de los ríos, entre otros. No obstante lo anterior, la proliferación de instrumentos de planeación ha generado mayores problemas, particularmente en municipios con bajas capacidades territoriales que tienen que ajustar su ordenamiento territorial y generar múltiples planes para cumplir cada uno de estos requerimientos. 
Por ejemplo, un territorio tan pequeño como las islas principales del archipiélago de San Andrés, Providencia y Santa Catalina, debe articular más de 19 nuevos instrumentos de planeación con su Plan de Ordenamiento Territorial, lo que ha derivado en una recarga para las administraciones municipales y la Corporación Autónoma con jurisdicción en él.

En respuesta a esta problemática el Ministerio de Ambiente ha iniciado un proceso de consolidación de los diferentes instrumentos en uno solo que se articule a los otros sectores, asegurando la transversalidad del tema, siguiendo la recomendación hecha por la Organización para la Cooperación y el Desarrollo Económicos (OCDE) en el marco del proceso de adhesión de Colombia a esta organización (OCDE, 2014).

Como lo muestra el ejemplo del sector ambiental, el problema es que las EE. TT. con bajas capacidades institucionales se ven recargadas con la exigencia de crear nuevos instrumentos de planeación territorial, lo cual podría obviarse teniendo en cuenta que sobre quienes recae esta responsabilidad suelen ser los mismos funcionarios encargados de la formulación de los múltiples planes sectoriales, entre los que se encuentra el respectivo PAT. El riesgo es que ello derive, como lo observa la oCDE (2014) en el caso ambiental, en una proliferación de instrumentos que se formulan para dar cumplimiento a los requisitos legales, sin que repercutan en la temática que regulan y sin que estén realmente incorporados al ciclo de planeación de las EE. TT.

Otro problema del sistema de planeación paralelo es que implica coordinar al menos diez instrumentos sectoriales del sistema de atención a víctimas con por lo menos seis del ciclo de planeación y presupuestación de las EE. TT., sin contar los de planeación de otros sectores, ${ }^{12}$ lo cual es complicado no solo por el número de planes e instrumentos que se deben formular y articular, sino por la baja capacidad institucional de las EE. TT., puesto que no cuentan con un número suficiente de funcionarios capacitados para desarrollar las múltiples funciones que les son asignadas (OCDE, 2013).

Así mismo, la articulación de los dos sistemas se complejiza por la falta de claridad sobre la coordinación de los ciclos de formulación, aprobación y seguimiento de los instrumentos. Este hecho se trató de remediar en el artículo 255 del Decreto 4800 de 2011, al atar la vigencia del PAT a la vigencia del gobierno de las autoridades locales. Sin embargo, la coincidencia en la vigencia no conlleva necesariamente la articulación de los dos sistemas de planeación. De hecho, esta coincidencia en los tiempos puede llevar a que las autoridades locales, particularmente el secretario de Planeación de la correspondiente EE. TT., deje en segundo plano la elaboración del PAT por atender sus obligaciones respecto a la formulación del PDT, que es una tarea prioritaria contenida de manera explícita en los manuales de funciones de su cargo.

Tampoco la normatividad es clara sobre cuál debe alimentar al otro: el PAT tiene información

\footnotetext{
12 Entre los instrumentos sectoriales del sistema de atención a víctimas están: el Plan de Acción Territorial (PAT), el Plan Nacional de Atención a Víctimas, el Plan Integral Único (PIU), el Plan Operativo de Información, el Plan de Contingencia, el Plan Integral de Prevención, los Planes Integrales de Retorno y Reubicación, el Plan Integral de Reparación Colectiva para Pueblos y Comunidades Indígenas (PIRPCI), el Plan Integral de Reparación Colectiva para Comunidades Negras, Afrocolombianas, Raizales y Palenqueras (PIRC) y el Plan Integral de Reparación Colectiva al Pueblo Rom o Gitano.
} 
útil sobre las víctimas y la estrategia de atención a estas, la cual sirve de insumo para la elaboración del PDT; al mismo tiempo, el PDT aporta al PAT las líneas estratégicas de gestión para el cuatrienio, en las que se deben incluir los recursos para la atención y reparación de las víctimas. Al no existir una lógica en la articulación, ni una definición tajante del momento de formulación de cada uno de estos dos instrumentos, ni sobre cuál debe alimentar al otro, es muy difícil para la oficina de planeación de la entidad territorial saber cómo proceder y cómo coordinarse con el CTJT, que es el encargado de aprobar el PAT.

Lo que sí es claro es que el PAT, además de articularse con el PDT, debe: 1) atender los lineamientos del marco fiscal de mediano y largo plazo en la planeación de las acciones, programas y proyectos relacionados con la atención y reparación de las víctimas; y 2) articularse de tal modo al sistema general de planeación territorial, que los compromisos y estrategias contempladas por el cтJ deben quedar consolidados en el Plan Indicativo y tener recursos asignados en el Presupuesto Anual y en el PoAl.

Finalmente, la articulación de los dos sistemas implica también consolidar en el Programa Anual de Caja (PAC) las diferentes estrategias, políticas y proyectos para la atención y reparación de las víctimas a cargo de cada una de las dependencias de la entidad territorial.

La desarticulación del sistema de atención y reparación de las víctimas con el sistema de planeación de las EE. TT. puede generar problemas como la no asignación de recursos y, por consiguiente, el que la ejecución de programas, planes y proyectos para atender a esta población se aplace o se suspenda, lo que la afectará en el goce efectivo de sus derechos. Lo anterior sucede por la rigidez del ciclo presupuestal, que determina que instrumentos posteriores como el Presupuesto o el Plan Indicativo no puedan modificar lo dispuesto en el Plan de Desarrollo (DNP 2012b, p. 25).

Otra repercusión de no incluir líneas específicas para la atención a víctimas en el Plan de Desarrollo y los demás instrumentos del ciclo presupuestal de las EE. TT., desde la perspectiva de los funcionarios, es que puede acarrearles procesos disciplinarios por no estar ejerciendo debidamente las competencias legales relacionadas con la atención de las víctimas, o no estar cumpliendo con las disposiciones adicionales establecidas por la Corte Constitucional en los autos de seguimiento a la sentencia T-025 de 2004.

Un tercer problema que se puede generar debido a la desarticulación de los instrumentos mencionados es la ilegalidad de actos administrativos de las EE. TT. Un ejemplo particular es la ilegalidad del acto administrativo que expide el PDT si en este no se incluyen estrategias y proyectos para la atención y reparación de las víctimas (Ley de Víctimas, art. 174).

\section{La aplicación diferencial de la política de atención y reparación a las víctimas}

La Ley de Víctimas y sus decretos reconocen la necesidad de aplicar de manera diferencial la 
política pública teniendo en cuenta las disparidades entre las EE. TT. Este aparte del documento se enfocará en identificar este aspecto y cómo ello repercute en la caracterización de las EE. TT. Por ello, si bien no se hace referencia explícita a los стJт, sí se los tiene en cuenta al entender los municipios y departamentos no como instituciones político administrativas sino como jurisdicciones donde se enmarca el funcionamiento de dichos comités.

El Ilamado a aplicar una política territorial diferencial está contenido particularmente en el artículo 248 del Decreto 4800 de 2011, donde se obliga a la Unidad de Víctimas, en coordinación con el DNP, a adoptar el índice de capacidad territorial (ICT), mediante el cual se reconozca la diversidad entre las diferentes EE. TT. del país en los siguientes aspectos: a) Capacidad fiscal, administrativa e institucional; b) Necesidades básicas insatisfechas; y c) Índice de presión y necesidades particulares de la entidad territorial en relación con la prevención, atención y reparación integral de las víctimas.

Con base en este mandato, la Unidad de Víctimas y el DNP construyeron el Ict en el año 2012, teniendo en cuenta las siguientes variables: índice de capacidad de inversión (ICI); índice de pobreza multidimensional (IPM); índice histórico de presión; índice histórico de intensidad; subíndice de hechos contra la población civil; participación de las víctimas; presencia de grupos étnicos y pronunciamientos judiciales (DNP y UARIV, 2012, p. 1). ${ }^{13}$

13

El índice de capacidad de inversión (ICI) de las entidades territoriales
La clasificación de los municipios del país de acuerdo con dicho índice se puede observar en el mapa 1 del anexo. Los municipios con índice "alto" requieren mayor asistencia de la UARIv y los de índice "bajo" los que tienen mayor capacidad para la atención a víctimas.

\section{1 ¿Una verdadera aproximación diferencial en lo territorial?}

Lo que se puede concluir de la Ley de Víctimas, el Decreto 4800 y los documentos Conpes 3726 de 2012 y 3784 de 2013 es que, reconociendo la heterogeneidad de las EE. TT., se debería hacer una aproximación diferencial teniendo en cuenta las capacidades de los municipios y departamentos, mediante el Iст. Sin embargo, fuera de este "deber ser" el resto de la normatividad no especifica cómo es que las EE. TT. van a recibir un trato diferencial en lo territorial con base en sus características específicas. Por ello, el reto de los стנт, y sobre todo de las entidades rectoras del SNARIV, es diseñar los mecanismos para aplicar de manera diferencial la política de atención y reparación a las víctimas. Así mismo, la Unidad de Víctimas y el DNP tienen el reto particular de adecuar el Iст para que realmente sirva de base para las decisiones que implique el trato diferencial en lo territorial. Cada uno de estos dos retos se explicará a continuación.

se calcula con base en variables fiscales como los recursos propios o los recursos distribuidos, atendiendo a la reforma del Sistema General de Regalías. El índice de pobreza multidimensional (IPM) evalúa el desempeño de los hogares en 15 variables agrupadas en cinco dimensiones: condiciones educativas del hogar; condiciones de la niñez y la juventud; salud; trabajo; acceso a servicios públicos domiciliarios y condiciones de la vivienda. Más información sobre estos componentes está disponible en DNP y UARIV (2012 y 2014). 
A la fecha no existe un mecanismo para adecuar las responsabilidades de las EE. TT. a su capacidad de gestión pública, de ahí que los instrumentos relacionados con la aplicación de la Ley de Víctimas que deben elaborar no muestren ninguna diferencia a nivel territorial en la formulación, implementación, seguimiento y evaluación. Esto contradice el concepto de trato diferencial territorial contenido en la citada ley. De hecho, el artículo 248 del Decreto 4800 indica que la Unidad de Víctimas debe construir para las EE. TT. los instrumentos estandarizados para realizar el seguimiento y evaluación de los planes de acción y para evaluar su contribución en el desarrollo de las acciones de prevención, asistencia, atención y reparación integral a las víctimas.

Consecuentemente, las responsabilidades en la formulación de instrumentos, implementación de las acciones y elaboración de reportes son las mismas para todas las EE. TT., tampoco hay una especificación explícita sobre cuándo entran a operar los principios de subsidiariedad y complementariedad contenidos en la ley, y a los que ha hecho referencia la jurisprudencia constitucional -v. gr. autos 383 de 2010 y 099 de $2013^{14}$ de seguimiento a la sentencia T-025 de 2004-. La Unidad de Víctimas ha utilizado el ICT para prestar su asistencia técnica o para la regionalización de proyectos de inversión (DNP y UARIV, 2013). No obstante lo anterior, dicha prác-

14 En el Auto 383 de 2010, ver en particular la sección IV sobre "principios constitucionales relevantes para la coordinación entre la Nación y los territorios" y en el Auto 099 de 2013 la sección 1.2.1. sobre "valoración (de) la respuesta estatal en relación con el conjunto de falencias atribuibles a las entidades territoriales" en la entrega de la ayuda humanitaria. tica no parece materializar el trato diferencial en la política pública, por lo menos como quedó contenida en el marco normativo de la Ley de Víctimas, en el Decreto 4800 y en el Plan Nacional de Atención y Reparación a las Víctimas (Conpes 3726 de 2012), pues no se está reconociendo a los municipios y departamentos sus capacidades institucionales, ni las características propias de su población y de las víctimas que en estos habitan.

\subsection{Problemas del índice de capacidad territorial (ICT) para la caracterización} de EE. TT.

El ICT se presenta como una primera alternativa para la diferenciación de las EE. TT. en lo referente a la atención y reparación de las víctimas. Sin embargo, este primer esfuerzo adelantado por la Unidad de Víctimas y el DNP podría ser revisado para lograr una mejor caracterización de los municipios y departamentos frente al trato territorial diferencial contenido en el marco normativo que regula la atención y reparación a las víctimas, y al que ya se ha hecho referencia.

El Decreto 4800 es claro al indicar que el ICT debe enfocarse en: (i) capacidad fiscal, administrativa e institucional; (ii) necesidades básicas insatisfechas; y (iii) índice de presión y necesidades particulares de la entidad territorial en relación con la prevención, atención y reparación integral de las víctimas. El primer componente se expresa a través del índice de capacidad de inversión (ICI), el segundo mediante el índice de pobreza multidimensional (IPM) y el tercero se evalúa de acuerdo con las seis variables sectoriales del tema de víctimas, ya descritas. 
A continuación se explicará por qué consideramos que el Іст no utiliza las mejores variables para describir los tres factores señalados por el Decreto 4800, antes mencionados. Además, tiene un sesgo hacia variables del sector de atención y reparación a las víctimas, que si no reciben un tratamiento estadístico particular -como ponderaciones o asignación de pesos relativos-, podrían generar distorsiones en la caracterización de las EE. TT. ${ }^{15}$

El primer problema de esta aproximación es que el Ic describe la capacidad de inversión de las EE. TT. pero no es una medida válida para la evaluación de las capacidades fiscales -que tradicionalmente se miden a través del índice de desempeño fiscal-o de las capacidades administrativas e institucionales de las EE. TT. - que el DNP evalúa a través del índice de desempeño integral-. El ICl, que se calcula como se vio en la nota 20 a pie de página, ${ }^{16}$ le da mayor relevancia a la capacidad de inversión de las EE. TT., independiente de las capacidades institucionales que tengan para el ejercicio de sus competencias o de la apropiación de recursos.

15 Los índices o indicadores compuestos suelen construirse incluyendo múltiples variables explicativas en diferentes dimensiones, cada una de las cuales recibe un peso relativo dependiendo de su importancia para el índice. El problema con la construcción actual del ıст es que no ponderó de manera diferenciada cada una de las dimensiones que se debían observar, a saber: (i) capacidad institucional, (ii) necesidades básicas insatisfechas y (iii) variables relacionadas con el tema de la vulnerabilidad de las víctimas. Al no realizar la ponderación de cada variable se observa que todas tienen el mismo peso, pero de las ocho variables seis hacen referencia a la misma dimensión: víctimas. En la práctica lo que sucede es que las capacidades institucionales y las necesidades básicas insatisfechas pierden mucho peso en el puntaje del índice y no son relevantes para la diferenciación de las EE. TT., como sí lo sugiere la Ley de Víctimas y el Decreto 4800 .

Ver descripción de este índice en la nota 20 a pie de página.
Lo que sucede al utilizar el ICl es que se privilegian algunos municipios que tienen mayores recursos, particularmente aquellos que participan del sistema general de regalías, pero ello no quiere decir que estos municipios sean los que tienen mayores capacidades territoriales para la ejecución de los recursos. Este enfoque fiscal puede generar caracterizaciones equivocadas 0 imprecisas de las capacidades de las EE. TT. ${ }^{17} \mathrm{~A}$ partir de este problema, en la práctica los principios de subsidiariedad y complementariedad solo operarían para las EE. TT. con bajas capacidades de inversión, ${ }^{18}$ lo que desdibuja la realidad institucional de los municipios con altos ingresos por regalías. Por ello, lo que se espera es que la Unidad de Víctimas, en atención al trato diferencial territorial, apoye con más recursos a las EE. TT. con altas capacidades institucionales y bajas capacidades de inversión, y con asistencia técnica a municipios con altas capacidades de inversión y bajas capacidades institucionales. Con ello se lograría un trato diferencial de las EE. тT., que contribuiría a una mejor atención y reparación a las víctimas.

El segundo problema respecto de la forma como fue construido el Ict es el peso que tienen las variables del sector de atención y reparación a las víctimas sobre la calificación total del índice. Si bien es pertinente incluir variables sectoria-

17 Por ejemplo, el índice de desempeño integral del DNP evalúa además del aspecto fiscal otros cuatro componentes de la gestión pública de las EE. TT.: eficiencia, eficacia, cumplimiento de requisitos legales y capacidad administrativa. Para más información ver DNP (2013).

18 Es decir, con pocos recursos disponibles para inversión o con baja capacidad de endeudamiento, lo que no necesariamente implica que sean municipios con desempeños fiscales deficientes (DNP, 2012c, pp. 9-113). 
les, la preocupación es que no hay métodos de ponderación de estas. ${ }^{19}$ Por ello, la sugerencia sería modificar el índice de modo que cada uno de los tres componentes contemplados en la Ley de Víctimas (capacidad institucional, necesidades básicas insatisfechas y vulnerabilidad de las víctimas) tenga un peso similar y que este no se desequilibre por la introducción de más variables.

La solución es metodológica y consiste, por ejemplo, en otorgar pesos a las variables aplicando métodos estadísticos como el análisis de componentes principales o la metodología de Alkire y Foster (2011), utilizada para calcular el IPM. Metodológicamente existen múltiples soluciones que se podrán refinar una vez se tenga mayor claridad sobre la utilidad del ICT y la aceptación de la propuesta conceptual que lo respalda.

\subsection{Reflexiones sobre el trato diferencial a las EE. TT.}

La Ley de Víctimas introdujo acertadamente un trato diferencial en lo territorial para la implementación de la política de atención y reparación a las víctimas. Para esto propuso la elaboración del ıст como instrumento diferenciador de las capacidades de las EE. TT., de las características de la población que las habita, de las dinámicas del conflicto y de las víctimas. Si bien es cierto que este indicador aún presenta algunas deficiencias, fundamentalmente en la manera

19 En el documento técnico de construcción del índice no es posible identificar el uso de métodos de ponderación que asignen pesos a las variables para que los tres temas contenidos en el Decreto 4800 tengan igual relevancia en la caracterización de las EE. TT. que describe las capacidades institucionales de las EE. TT., el mayor problema a la hora de hacer un trato diferencial territorial en la aplicación de la Ley de Victimas es la estandarización de todos los otros instrumentos de planeación, ejecución y evaluación establecidos en esta y del apoyo técnico que se presta a las EE. TT.

En la medida que no se implemente un enfoque diferencial territorial en la política y se avance en definir los determinantes para la activación de los principios de coordinación y subsidiariedad, la mayoría de las EE. TT. continuarán desbordadas por las obligaciones que les impone la política de atención y reparación a las víctimas. Lo anterior repercute en el buen desempeño de los стנт, pues su operación se enmarca en las características estructurales de su territorio y las variables externas determinantes para la ejecución de sus funciones, como por ejemplo, la capacidad institucional de los departamentos o municipios.

\section{Retos frente a la articulación entre los CTJT y otras instancias del Estado que adelantan procesos administrativos y judiciales que también involucran a las víctimas del conflicto}

De acuerdo con lo establecido en la Ley 1448 de 2011, las acciones estatales en favor de las víctimas del conflicto deben estar articuladas, en lo local, por la instancia de los cтנт. Sin embargo, existen dos "megaprocesos" estatales que involucran a las víctimas, y que no fueron incorporados de manera explícita en la reglamentación actual de las competencias y miembros 
de los ctנt: la restitución de tierras y territorios, y la aplicación de la Ley de Justicia y Paz.

En el primero, de acuerdo con la información publicada por la Unidad de Restitución de Tierras, ${ }^{20}$ se han proferido 386 sentencias en 13 departamentos del país. En varias de estas se dan órdenes específicas a las autoridades locales, relativas a diferentes ámbitos de la gestión pública, ${ }^{21}$ que deberían ser articuladas con otras acciones que se vienen adelantando en favor de las víctimas. En el segundo, la Unidad de Víctimas ha señalado que está ejecutando las órdenes de ocho sentencias de Justicia y Paz, que tienen cubrimiento en once departamentos (Gobierno Nacional, 2013, p. 17 y 2014, pp. 264-266). Al igual que las sentencias sobre restitución de tierras, las de Justicia y Paz les dan órdenes específicas a las autoridades locales. En algunos casos, en la providencia judicial, les han ordenado la ejecución de obras y la provisión de ciertos servicios a las víctimas.

Ninguno de estos dos procesos está contemplado de manera explícita dentro de la órbita de acción de los стנт. Adicionalmente, las respectivas entidades rectoras de estos procesos (Unidad para la Restitución de Tierras y Jurisdicción de Justicia y Paz) no son miembros permanentes de los стנт. No obstante, las decisiones adoptadas al interior de cada uno sí impactan en lo

20 Disponible en: $\mathrm{http}: / /$ restituciondetierras. gov $\mathrm{co} /$ ?action=category\&id= 34 , consultado en julio 30/14.

21 Al respecto, la Unidad de Restitución de Tierras conformó un grupo de monitoreo a los fallos de restitución, que cuenta con una base de datos con todas las órdenes proferidas en estas sentencias y las autoridades nacionales y locales involucradas en el cumplimiento de estas. local lo programado en los PAT y en la agenda anual de trabajo de los cтst. Por tal razón, este constituye un reto adicional para los comités en cuanto a la articulación.

Un tercer megaproceso es el referente a la atención estatal de los desmovilizados de los grupos armados al margen de la ley, que también hace parte de las funciones generales de los стנт, ${ }^{22} \mathrm{a}$ pesar de que sus principales actores públicos no fueron incluidos como miembros permanentes de estos: la Agencia Colombiana para la Reintegración (ACR) y el Centro Nacional de Memoria Histórica, este último en lo referente a las contribuciones a la verdad en el marco de la Ley 1424 de 2010. Hasta ahora no se ha producido una directriz nacional disponiendo que estas dos entidades sean convocadas a las reuniones de los cтst en calidad de invitados, sin embargo, tal como se mencionó en apartes anteriores, los CTJT gozan de autonomía para invitar a entidades públicas, privadas y de la sociedad civil a sus reuniones.

La participación de estos dos entes en las sesiones de los CTJT daría mayor integralidad a las acciones de coordinación de estos, dado que las contribuciones de los victimarios son indispensables para esclarecer la verdad de los hechos (incluyendo el paradero de quienes aún continúan desaparecidos), y con ello, los derechos de las víctimas a la verdad, la justicia, las medidas de satisfacción y las garantías de no repetición. De igual manera, las manifestacio-

\footnotetext{
22 Ley de Víctimas, art. 173: "adoptar las medidas conducentes a materializar la política, planes, programas y estrategias en materia de desarme, desmovilización y reintegración".
} 
nes de arrepentimiento y solicitudes de perdón a las que algunos victimarios llegan dentro del proceso estatal de acompañamiento a su desmovilización y reintegración social son parte fundamental de las medidas de satisfacción de las víctimas, al contribuir a la mitigación de su dolor y a proporcionarles bienestar.

\section{B. Retos internos para los CTJT}

\section{Frente a la participación de los representantes de las víctimas}

Los dos representantes de las víctimas en los comités y subcomités de justicia transicional de nivel municipal, distrital y departamental plantean al стJт el reto relacionado con la gestión oportuna de información y la postura de estos en las Mesas de Participación ${ }^{23}$ involucradas con los diversos temas de competencia de los СтJт, ${ }^{24}$ lo cual no es fácil si se tiene en cuenta (i) la oportunidad de su gestión, (ii) el número de entidades territoriales en las que tienen participación y que pueden estar involucradas en una determinada decisión de los cтנт, (iii) los medios que requieren para desarrollar sus funciones y (iv) el margen de incidencia que ellos

Sobre las Mesas de Participación de Víctimas, su origen, funcionamiento, retos y dificultades, ver: Berrío, J. M. (2013).

24 La participación de los representantes de las víctimas en el CTJT se encuentra regulada en la Ley de Víctimas, art.173 num. 11 y art. 193, parágrafo 3 . Respecto a su participación en los subcomités técnicos se debe resaltar que ni la Ley de Víctimas, ni el Decreto 4800 , ni el Protocolo de Participación Efectiva (resoluciones 388 y 588 de 2013) se refieren a la elección de los delegados de las víctimas ante estos. Lo que se ha visto en la práctica es que la Mesa de Víctimas escoge representantes diferentes para el CTJT y para los subcomités. Esto en aras de aumentar el número de miembros de la respectiva Mesa que tienen participación en las citadas instancias. tienen sobre las decisiones de los CTJT, dada la forma en que actualmente está regulado su funcionamiento.

La primera situación a superar frente a la participación de los representantes de las víctimas tiene que ver con la duración de sus gestiones, puesto que debe estar perfectamente sincronizada con los cronogramas de trabajo y decisión de los сттт y de los subcomités. Es decir, los aportes de las víctimas y sus representantes deben ser presentados a tiempo dentro del proceso de análisis y decisión que se esté surtiendo tanto en los subcomités como en los cтJт. Para esto, los representantes de las víctimas y los demás miembros de los subcomités y del cтנt, incluido quien ejerza la secretaría técnica por delegación del alcalde o del gobernador (D. 4800/2011, art. 253, párr. 2), deben fijar unos plazos para el análisis y decisión de los asuntos en las Mesas de Participación, que hagan posible la convocatoria previa de estas, la circulación de la información relevante con la debida antelación, la reunión, la deliberación, la definición de la posición y la adopción de decisiones. La fase de deliberación y toma de decisiones puede ser compleja y requerir de más de una reunión, dependiendo del tema que se esté tratando, el contexto regional específico, el tipo de relaciones existentes entre los miembros de la Mesa y las dinámicas de funcionamiento de esta.

El segundo aspecto que se debe considerar frente al reto de la participación de los representantes de las víctimas en las deliberaciones y decisiones de los стJ es que estas no siempre involucran a una sola entidad territorial y, en 
ciertos casos, inclusive, a entidades de diferente nivel jerárquico (municipio y departamento). Esto les implica a los representantes de las víctimas ponerse en contacto y gestionar acuerdos con sus pares de los otros cтJ municipales y departamentales vinculados con la materia objeto de estudio y con las respectivas mesas de víctimas a quienes representan. Esto ocurre, por ejemplo, en los procesos de reparación de sujetos colectivos que tengan presencia en más de un municipio, o en los que vaya a participar el (o los) respectivo(s) departamento(s) o la Nación. Los representantes de las víctimas en los diferentes стJт y subcomités involucrados deberán articularse entre sí, así como con los representantes del colectivo que está siendo sujeto del proceso de reparación. Algo similar sucede en los procesos de retorno, en los que usualmente está involucrada más de una entidad territorial, salvo en el caso de los desplazamientos intraveredales e intraurbanos; por tal razón, los representantes de las víctimas de los respectivos CTJT deberán gestionar acuerdos entre sí y mantener una comunicación fluida, así como con el colectivo beneficiario del proceso de retorno.

El tercer aspecto de este reto hace referencia a los medios requeridos por los representantes de las víctimas para desarrollar las actividades antes descritas en una o varias entidades territoriales involucradas en los asuntos que estén abordando los respectivos cTJT. Para ello, es indispensable que los representantes cuenten con recursos suficientes para hacer llamadas, transportarse y tener acceso a Internet para circular información. De igual manera, deben disponer de lugares dónde reunirse, contar con medios para preparar documentos y tener flexibilidad en sus horarios laborales. Adicionalmente, deben tener garantizada su alimentación y hospedaje cuando realicen gestiones fuera del lugar donde residen.

La financiación de estas actividades debe estar contemplada en los PAT y, de requerirse, debe ser complementada por el Gobierno Nacional. Al respecto, el Protocolo de Participación (Resolución 388 de 2013, art. 50) establece lo siguiente:

El financiamiento de los Espacios de Participación será compartido entre el Gobierno Nacional y los Gobiernos Municipales, Distritales y Departamentales bajo los criterios de complementariedad, concurrencia y subsidiariedad (...) Será obligación de los entes territoriales definir recursos específicos en el Plan de Acción Territorial -PAT- para el funcionamiento de las respectivas Mesas de Participación, indicando claramente el aporte propio y los fondos de cofinanciación solicitados.

Los recursos destinados a la participación de los representantes de las víctimas en los стJ y en los subcomités deben ser de un monto tal que les permita ejecutar las actividades que les corresponden, de manera completa y oportuna, en las entidades territoriales que estén involucradas en los temas objeto de desarrollo de los стנT. En caso de que tales actividades no estén financiadas o que los recursos no sean suficientes, los representantes de las víctimas se verán abocados a restringir parcialmente su ámbito de acción. Deberán intentar cumplir con sus responsabilidades, en los tiempos establecidos 
por la dinámica de trabajo de los CTJT, y consultando a todas las instancias de participación involucradas.

El cuarto aspecto del reto de la participación de los representantes de las víctimas es la posibilidad de incidencia efectiva en las decisiones de los CTJT, dadas las normas de funcionamiento actuales. Tal como se señaló en apartes anteriores, la Ley de Víctimas y el Decreto 4800 de 2011 crearon los стנт como entes colectivos, compuestos por una multiplicidad de miembros de diferentes orígenes y representaciones (entidades administrativas del orden nacional y territorial, la fuerza pública, el ministerio público y las organizaciones de víctimas de la región). Los representantes de las víctimas en los cTJT gozan de los mismos derechos y obligaciones que cualquier otro miembro de estos, no obstante, los "números" y las relaciones de poder (actuales y del pasado) no los favorecen. Tampoco los prejuicios que algunos miembros del CTJT pueden tener en su contra, incluyendo aquellos referentes a que su presencia hace más lento el ritmo de trabajo del Comité. ${ }^{25}$

Ni la Ley de Víctimas, ni el Decreto 4800 establecen las reglas aplicables para la toma de decisiones en los cтנt, de ahí que algunas entidades territoriales hayan adoptado el consenso ${ }^{26}$ y no la mayoría simple. Esto genera que solo cuando

25 Sobre las dificultades que afrontan las poblaciones vulnerables en los procesos de formulación y aprobación de políticas públicas, ver Lemaitre (2013).

26 Tal es el caso, por ejemplo, de los CTJT de Cundinamarca y de Barrancabermeja. Ver al respecto el art. 4 del Decreto 023 de 2012 de la Gobernación de Cundinamarca y el art. 5 del Decreto 033 de 2012 de la Alcaldía de Barrancabermeja. exista consenso se apruebe una medida y que se niegue en caso contrario, lo cual no resulta sencillo respecto a las propuestas presentadas por los representantes de las víctimas al cTJT.

\section{Frente a la interpretación de las normas que regulan el funcionamiento de los CTJT}

Al revisar las normas que regulan las funciones de los CTJT $^{27}$ se evidencia falta de claridad suficiente en lo referente al alcance de sus funciones y a la manera en la que se deben articular los стJт de diferentes entes territoriales (incluso de diferente jerarquía), involucrados en un mismo proceso de atención o reparación a las víctimas. Tal como se expuso en la sección anterior, tampoco existe claridad frente a la manera como operan los principios de descentralización territorial, el reconocimiento del enfoque diferencial en lo territorial ni frente a la articulación del ciclo de planeación establecido en la Ley de Víctimas con el ciclo general de planeación de las EE. TT.

Para ilustrar la falta de claridad de algunas de las normas que regulan las funciones de los CTJT se van a analizar dos ejemplos, uno referente a la reparación colectiva y otro frente a los planes de retorno. Frente a la reparación colectiva, el inciso 3 del artículo 230 del Decreto 4800 de 2011 establece lo siguiente: "la Unidad Administrativa Especial para la Atención y Reparación Integral a las Víctimas y el respectivo Comité Territorial de Justicia Transicional aprobará (sıc) el

27 Ley de Víctimas y decretos 4800, 4633, 4634 y 4635 de 2011. 
Plan Integral de Reparación Colectiva". Sin embargo, la legislación no establece criterios para determinar cuál es el "respectivo" Comité en caso que el sujeto objeto de reparación colectiva tenga presencia en más de una entidad territorial, ni para definir cuándo la aprobación del plan es competencia del Comité Departamental de Justicia Transicional.

El parágrafo 2 de este mismo artículo establece, con poca claridad, un caso en el que la aprobación del Plan Integral de Reparación Colectiva es de competencia exclusiva de la Unidad Administrativa Especial para la Atención y Reparación Integral a las Víctimas: cuando los sujetos de reparación colectiva "no estén ubicados en un ámbito territorial". Esta extraña categoría de sujetos colectivos sin ubicación territorial ha sido interpretada en la práctica por la Unidad de Víctimas como que hace referencia a "organizaciones sociales y políticas y los grupos altamente victimizados por el conflicto armado, cuya reparación es fundamental para el restablecimiento del ejercicio de los derechos fundamentales" (Gobierno Nacional, 2013, p. 224).

Este tipo de sujetos ha sido denominado por la Unidad de Víctimas como "casos nacionales" y para su atención creó la Estrategia de Casos Nacionales (Gobierno Nacional, 2013, p. 224-225 y 2014, pp. 213-215). ${ }^{28}$ En esta categoría se encuentran los casos de la Unión Patriótica, la Universidad de Córdoba, los periodistas, el movimiento sindical colombiano, las corporaciones

28 Ver también UARIV (s.f). En este video, en el minuto 10:39 se hace referencia a la reparación colectiva de la Universidad de Córdoba como un caso nacional. públicas, concejales y diputados, la Asociación Nacional de Usuarios Campesinos (ANUC) y otras organizaciones defensoras de derechos humanos, entre las que están algunas de mujeres ${ }^{29}$ "con influencia a nivel nacional" (Gobierno Nacional, 2013, p. 225-226 y 2014, pp. 214-215). Esta interpretación del parágrafo 2 del artículo 230 del Decreto 4800 de 2011 da un amplio margen a la Unidad de Víctimas para determinar los planes de reparación colectiva cuya aprobación (mas no ejecución) son de su exclusiva competencia.

En materia de planes de retorno y reubicación, el Decreto 4800 define a los cTJT como un espacio de coordinación y seguimiento, y el "marco" en el que tales planes serán construidos, pero no les establece a los ctJT una función explícita frente a la aprobación de estos. Al respecto, el artículo 76 señala lo siguiente: "Las acciones de coordinación, planeación, seguimiento y participación de las víctimas incluidas en los procesos de retorno y reubicación se realizarán en el marco de los Comités Territoriales de Justicia Transicional bajo los lineamientos previstos en el Protocolo de Retorno y Reubicación" (cursivas añadidas). En concordancia con lo anterior, el artículo 78 del mismo decreto señala: “El Protocolo de Retorno y Reubicación incorporará los Planes de Retorno y Reubicación (...) Dichos Planes serán elaborados en el marco de los Comités Territoriales de Justicia Transicional".

29 Entre ellas: Narrar para Vivir, Liga de Mujeres Desplazadas, Organización Femenina Popular (OFP) y la Asociación Nacional de Mujeres Campesinas Indígenas y Negras de Colombia (ANMUCIC) capítulos de El Zulia y nacional. 
Adicionalmente, se debe resaltar que si bien en la Ley de Víctimas y en el Decreto 4800 no se hace una distinción entre los tipos de planes de retorno y de reubicación, en la práctica sí existe una subclasificación dependiendo del número de personas o familias involucradas. Están los retornos y reubicaciones individuales o familiares, que involucran hasta diez familias, y los retornos y reubicaciones masivas destinados a más de diez familias o más de cincuenta personas. ${ }^{30}$ Dependiendo del tipo de retorno o reubicación (individual o masivo) el rol de la Unidad de Víctimas y de los стנт es distinto. Sin embargo, esto no se encuentra regulado y será abordado en el protocolo para el acompañamiento a retornos y reubicaciones, en el marco de la reparación integral a la población víctima del desplazamiento forzado, que ha venido construyendo la Unidad.

\section{CONCLUSIONES}

El recorrido por la naturaleza, composición y funciones de los CTJT y los retos que preliminarmente hemos identificado que estos afrontan, busca evidenciar que gran parte de la eficacia (o ineficacia) de la apuesta estatal y de la acción de la sociedad colombiana frente a la Ley de Víctimas y de Restitución de Tierras dependerá del trabajo que en la práctica estos logren desarrollar, en el marco de los contextos heterogéneos y complejos donde deben operar.

30 La definición dada en el art. 12 del Decreto 2569 de 2000 sobre los desplazamientos individuales y los masivos se ha venido aplicando también para referirse a los retornos (individuales y masivos).
Esto porque la atención y la reparación de las más de 6 millones de víctimas que se encuentran inscritas a la fecha en el Registro Único de Víctimas, se debe prestar en la totalidad de los territorios donde ellas actualmente habitan o a donde quieren volver, y esto involucra nada más ni nada menos que a la totalidad de municipios y departamentos del país. En últimas, es en lo local donde se da la implementación de las obligaciones adquiridas por el Estado y la sociedad colombiana con las víctimas del conflicto armando, estipuladas en la Ley 1448. Por ello, es indispensable que en lo local exista una instancia participativa que: 1) coordine y le haga seguimiento a la ejecución articulada de la política de atención y reparación a las víctimas, 2) contribuya a que dicha política efectivamente se incorpore a la gestión territorial en sus distintos niveles y diferencias, y 3) vele porque se dé aplicación práctica a los principios de descentralización administrativa y territorial. En este sentido el gran reto de los cтJ será consolidarse como órganos rectores del proceso de atención y reparación a las víctimas en cada municipio o departamento, y lograr que dicha atención y reparación se ejecute de manera integral, posicionándola como un tema transversal que debe ser prioritario para todos los sectores y órganos del Estado colombiano.

El rol que han venido desempeñando en la práctica los más de 1000 comités departamentales y municipales de justicia transicional en la implementación de la Ley de Víctimas, es un área interesante de estudio y seguimiento por parte de la academia y las autoridades públicas. Este artículo pretendió también contribuir a incenti- 
var la realización de investigaciones posteriores en esta materia.

\section{Referencias}

ABColombia, Sisma Mujer y U.S. Office on Colombia. (2013). Colombia: mujeres, violencia sexual en el conflicto y el proceso de paz. Recuperado el 7 de septiembre de 2014 de abcolombia.org: http://www.abcolombia.org. uk/downloads/Sexual_violence_report_Spanish.pdf

Alkire, S. y Foster, J. (2011). Counting and multidimensional poverty measurement. Journal of Public Economics, 476-487.

Arellano, D. (2007). Una cuestión de confianza. Retos e instrumentos para una reforma del Estado en América Latina. Revista Nueva Sociedad, (210), 95-109.

Berrío, J. M. (2013). Las mesas de participación de víctimas: ¿una frustración más o un mecanismo de transformación social? Revista de Derecho Público, (31).

Cameron, E. y Green, M. (2004). Team change. En E. Cameron y M. Green, Making sense of change in management (págs. 54-66). Londres, Inglaterra: Kogan Page.

Centro Internacional para la Justicia Transicional y Programa de las Naciones Unidas para el Desarrollo. (2011). Recordar y reparar. Políticas públicas que hacen justicia. Cuatro temas en la agenda de reparación en Colombia. Bogotá, Colombia: ıcтJ.
Consejo Nacional de Política Económica y Social y Departamento Nacional de Planeación. (2012). Documento Conpes 3726: Lineamientos, plan de ejecución de metas, presupuesto y mecanismo de seguimiento para el plan nacional de atención y reparación a víctimas. Bogotá, Colombia: Autores.

Corte Constitucional de Colombia. Sentencia T-025 de 2004 (M. P.: Manuel José Cepeda Espinosa: enero 22 de 2004).

Decreto 2569 de 2000. [Presidencia de la República, Ministerio del Interior, Ministerio de Hacienda y Crédito Público]. Por el cual se reglamenta parcialmente la Ley 387 de 1997 y se dictan otras disposiciones. Diciembre 12 de 2000.

Decreto 033 de 2012. [Alcaldía Municipal de Barrancabermeja]. Por medio del cual se crea el Comité Municipal de Justicia Transicional de Barrancabermeja. Febrero 14 de 2012.

Decreto 4800 de 2011. [Ministerio del Interior]. Por el cual se reglamenta la Ley 1448 de 2011 y se dictan otras disposiciones. Diciembre 20 de 2011.

Decreto Departamental 023 del 2012 “por medio del cual se crea el Comité Territorial de Justicia Transicional del Departamento de Cundinamarca y se dictan otras disposiciones".

Decreto Departamental 023 del 2012 “por medio del cual se crea el Comité Territorial de Jus- 
ticia Transicional del Departamento de Cundinamarca y se dictan otras disposiciones".

Decreto Departamental 138 del 2012 "por medio del cual se modifica parcialmente el Decreto $n .{ }^{\circ} 0023$ del 9 de febrero de 2012, por el cual se crea el Comité Territorial de Justicia Transicional del Departamento de Cundinamarca y se dictan otras disposiciones".

Departamento Nacional de Planeación. (2012a). Planeación para el desarrollo integral de las entidades territoriales. Guía para la gestión pública territorial $n .^{\circ} 4$. Bogotá, Colombia.

Departamento Nacional de Planeación. (2012b). Instrumentos para la gestión pública territorial por resultados. Guía para la gestión pública territorial $n .^{\circ}$ 11. Bogotá, Colombia: Autor.

Departamento Nacional de Planeación. (2012c). Desempeño fiscal de los departamentos y municipios. Bogotá: Colombia.

Departamento Nacional de Planeación. (2013). Evaluación del desempeño integral 2012. Bogotá: Autor.

Departamento Nacional de Planeación y Unidad para la Atención y Reparación Integral a las Víctimas. (2012). Construcción del índice de capacidad territorial. [Documento interno de trabajo]. Bogotá: Autores.

Departamento Nacional de Planeación y Unidad para la Atención y Reparación Integral para las Víctimas. (2013). Cartilla de lineamientos para la regionalización de proyectos de in- versión que atiendan a población víctima del conflicto armado. Bogotá: Autores.

Departamento Nacional de Planeación y Unidad para la Atención y Reparación Integral para las Víctimas. (2014). Lineamientos para la regionalización de proyectos de inversión dirigidos a la atención, asistencia y reparación integral a víctimas del conflicto armado. Bogotá: Autores.

Gobierno Nacional. (2013). Informe del Gobierno Nacional para las Comisiones Primeras de Senado y Cámara. Bogotá: Autor.

Gobierno Nacional. (2014). Informe del Gobierno Nacional a las Comisiones Primeras del Congreso de la República. Bogotá: Autor.

Human Rights Watch (2014). Resumen de país: Colombia. Recuperado el 7 de septiembre de 2014 de hrw.org: http://www.hrw.org/ sites/default/files/related_material/colombia_sp_4.pdf

Jaramillo, S. (2014). La paz territorial. En Entérese del proceso de paz (págs. 11-15). Bogotá, Colombia: Oficina del Alto Comisionado para la Paz.

Lemaitre, J. (2013) Diálogos sin debate: la participación en los decretos de la Ley de Víctimas. Revista de Derecho Público, (31).

Ley 99 de 1993. Por la cual se crea el Ministerio del Medio Ambiente, se reordena el Sector Público encargado de la gestión y conservación del medio ambiente y los recursos naturales 
renovables, se organiza el Sistema Nacional Ambiental, SINA, y se dictan otras disposiciones. Diciembre 22 de 1993. DO. n. ${ }^{\circ} 41.146$.

Ley 152 de 1994. Por la cual se establece la Ley Orgánica del Plan de Desarrollo. Julio 15 de 1994.

Ley 387 de 1997. Por la cual se adoptan medidas para la prevención del desplazamiento forzado; la atención, la protección, consolidación y estabilización socioeconómica de los desplazados internos por la violencia en la República de Colombia. Julio 18 de 1997.

Ley 1448 de 2011. Por la cual se dictan medidas de atención, asistencia y reparación integral a las víctimas del conflicto armado interno y se dictan otras disposiciones. Junio 10 de 2011. DO. n. ${ }^{\circ} 48.096$.

Ministerio del Interior, Ministerio de Justicia y del Derecho y Unidad para la Atención y Reparación Integral a las Víctimas. (s.f.). Guía para conformación y funcionamiento de Comités Territoriales de Justicia Transicional. Bogotá: Autores.

Ministerio del Interior, Ministerio de Justicia y del Derecho, Ministerio de Hacienda y Crédito Público, Departamento Nacional de Planeación y Unidad para la Atención y Reparación Integral a las Víctimas. (2012). Guía para la formulación y ajuste de los planes de acción departamentales, municipales y distritales para la prevención, atención, asistencia y reparación integral a las víctimas del conflicto armado. Bogotá: Autores.
Organización para la Cooperación y el Desarrollo Económico. (2013). Multi-Level Governance in Colombia. En oCDE, Colombia: implementing good governance, OECD Public Governance Review (págs. 205-270). París, Francia: OECD Publishing.

Organización para la Cooperación y el DesarroIlo Económico. (2014). OECD environmental performance reviews: Colombia 2014. París, Francia: OECD publishing.

Ostrom, E. (2003). Toward a behavioral theory linking trust, reciprocity, and reputation. En E. Ostrom y J. Walker, Trust and Reciprocity. Nueva York, Estados Unidos: Russell Sage.

Resolución 588 de 2013. [Unidad para la Atención y Reparación Integral a las Víctimas]. Por la cual se modifican disposiciones de la Resolución 0388 del 10 de mayo de 2013 por medio de la cual se adopta el Protocolo de Participación Efectiva de las Víctimas del Conflicto Armado y se dictan otras disposiciones. Junio 13 de 2013.

Unidad de Víctimas. (Junio 1 de 2014). Reporte general sobre las víctimas. Recuperado en julio 30/14 de unidadvictimas.gov: http:// www.unidadvictimas.gov.co/

Unidad para la Atención y Reparación Integral a las Víctimas. (s.f.). Ruta de reparación colectiva a víctimas [Video]. De: http://www.youtube.com/watch?v=1n5erSZ3v54 y http:// www.unidadvictimas.gov.co/index.php/en/ conozca-sus-derechos/ reparacion-integral 
Unidad para la Atención y Reparación Integral pación efectiva de las víctimas. Bogotá, Coa las Víctimas y Viva la Ciudadanía. (2013). Iombia: Editorial El Globo.

Instructivo pedagógico. Protocolo de partici-

\section{ANEXOS}

Gráfico 3. Naturaleza de los instrumentos de planeación

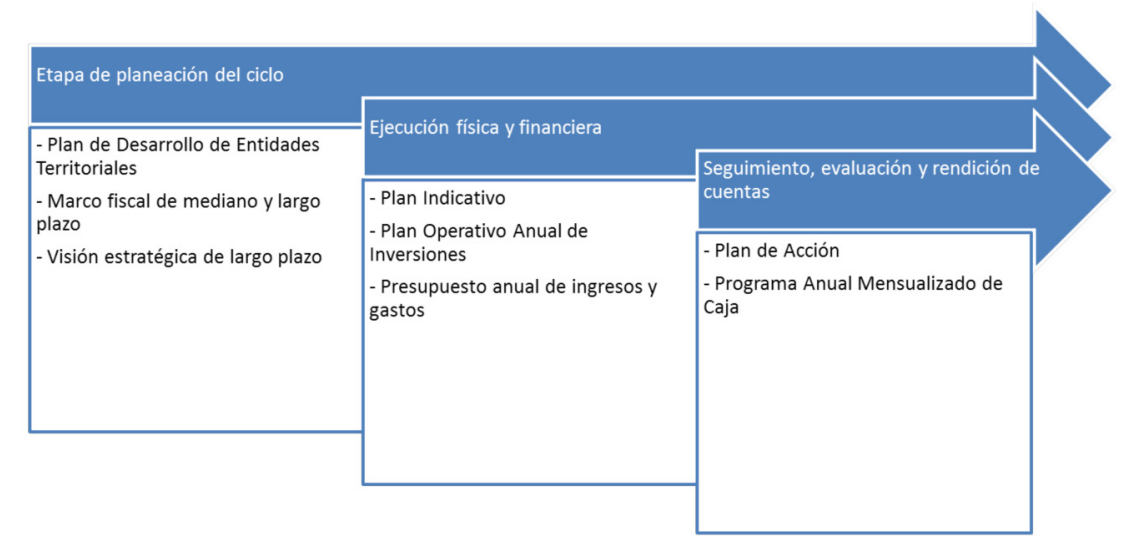

Fuente: elaboración propia con base en DNP (2012a y 2012b).

Gráfico 4. Encadenamiento de instrumentos de planeación

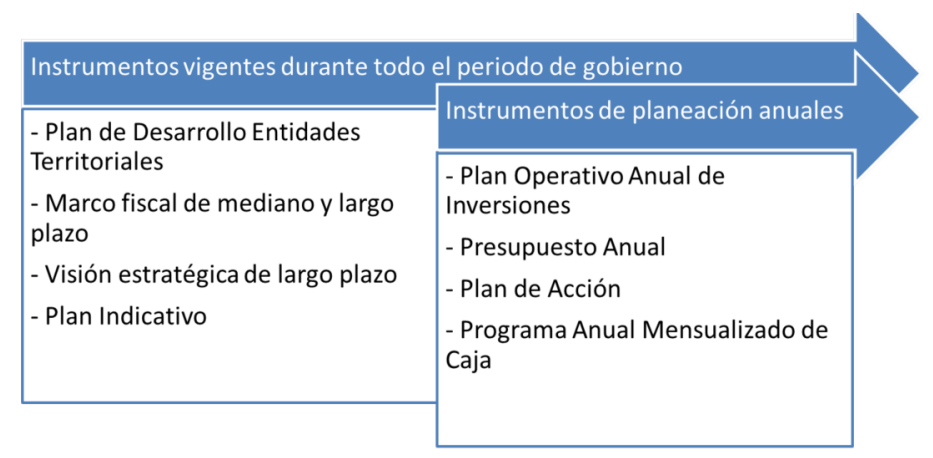

Fuente: elaboración propia con base en DNP (2012a y 2012b). 
Mapa 1. Índice de capacidad territorial (2012)

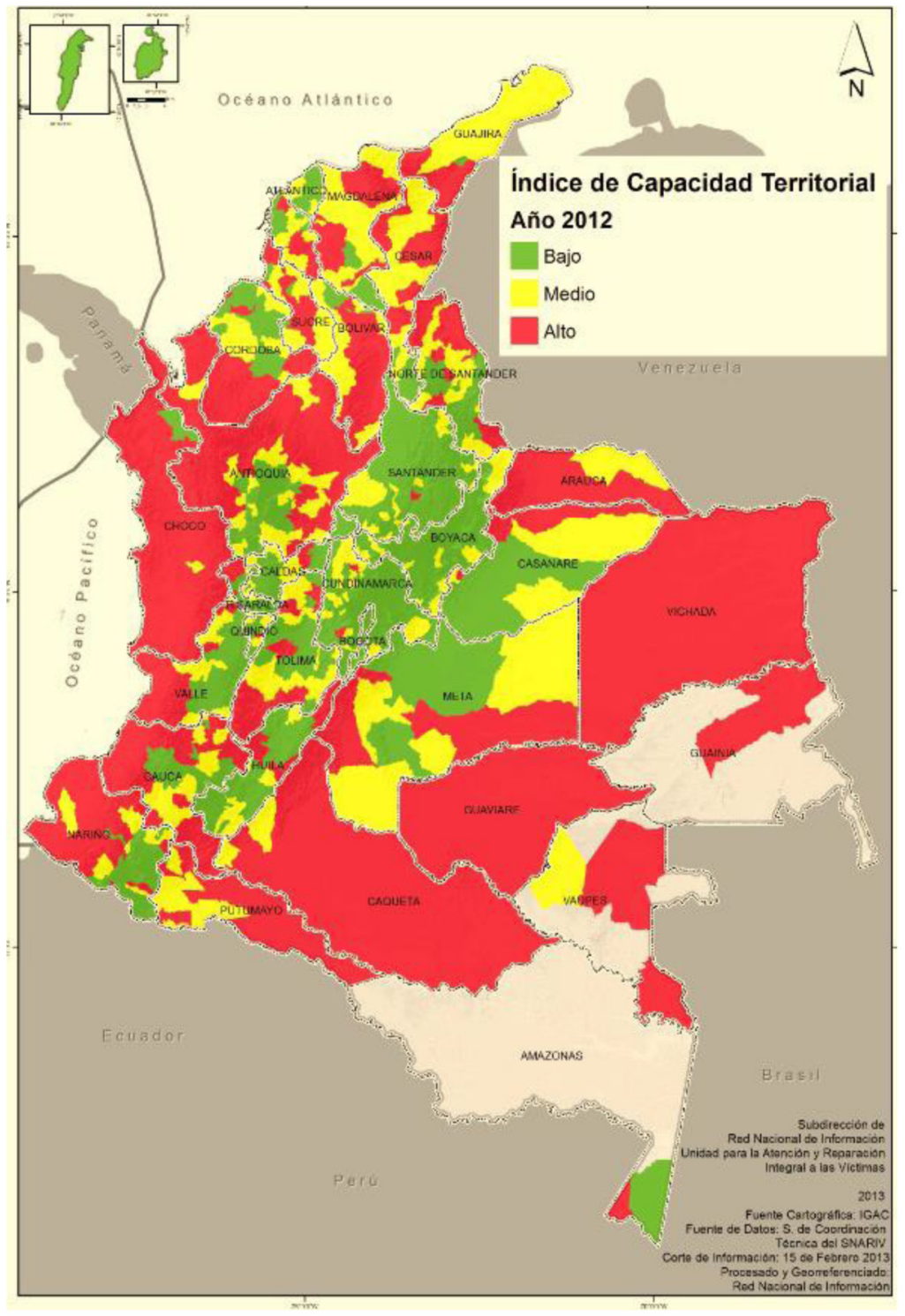

Fuente: DNP-UARIV: Construcción del índice de capacidad territorial.

El índice de capacidad territorial mide el riesgo que puede tener el proceso de atención a las víctimas. Por ello, los municipios con índice "alto" son los que requieren mayor asistencia de la uaRiv y los de nivel "bajo" los que tienen mayor capacidad para la atención a las víctimas. 